\title{
APPLICATION OF ELECTRONIC EVALUATION TOOLS IN BASIC EDUCATION SCHOOLS IN THE SOUTH AL BATINAH GOVERNORATE IN THE SULTANATE OF OMAN: A SOCIAL STUDIES TEACHERS' PERSPECTIVES
}

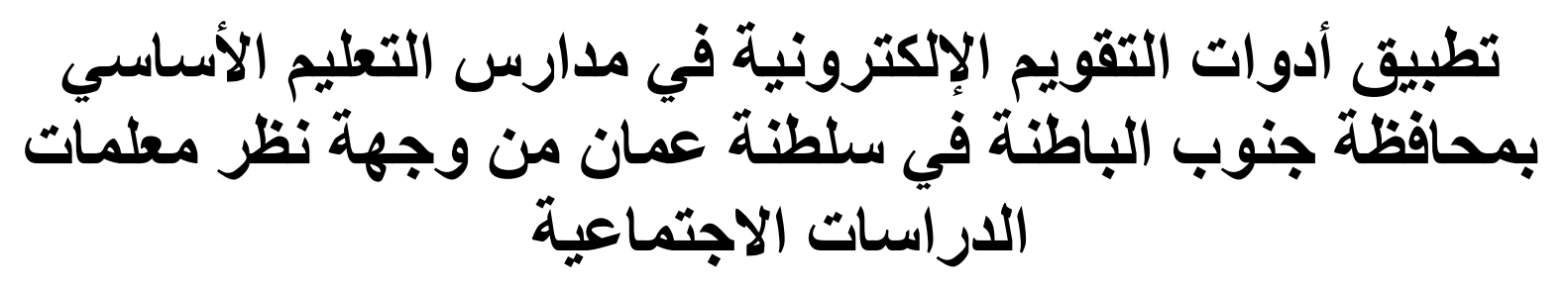

\author{
هدى خصيب حمدان الفزارية \\ Huda Khasib Hamdan AI Fazari ${ }^{1 \star}$, and Prof Dr. Mohammad Najib Jaffar ${ }^{2}$ \\ ${ }^{1} \mathrm{PhD}$. Candidate in education at the Faculty of Major Language Study, University Sains Islam \\ Malaysia (USIM), Huda.fazari@moe.om \\ ${ }^{2}$ Prof Madya Dr. at the Faculty of Major Language Study, University Sains Islam Malaysia (USIM), \\ najib@usim.edu.my \\ ${ }^{*}$ Correspondent author
}

\begin{abstract}
This qualitative study aimed to diagnose the applying of electronic evaluation tools in the social studies subject in Al-Batinah South schools, through the social studies teachers' perspectives. The problem has arisen in the lack of electronic calendar tools applications, due to the lack of capabilities of the parameters in the application of electronic calendar tools, due to the weakness of the infrastructure, which is related to the telecommunications and networks sector. The objectives of the study: To diagnose the electronic evaluation tools that are applied, the electronic programs used in those applications, with an indication of the advantages of the application and the applications' challenges. The study adopted the qualitative approach, the size of the study population reached (15) schools, and a sample of (15) social studies teachers who attended practical training for continuous electronic evaluation programs were selected, where individual interviews were conducted with them. Data was analyzed using the content analysis method. After analyzing the results of the interviews, the following results were reached: From the tools applied by social studies teachers, to evaluate students 'learning, electronic assignments, short questions, electronic tests, from the programs used in the application of tools Google drive, Zid jard, Padelt, as well as the advantages of applying tools. Electronic calendar, as the teachers affirmed the students 'desire to interact with applications of electronic assessment tools and the interactive solution, follow-up of student achievement, statistical analysis of student results, and reveal weaknesses and goals that students did not achieve. As for the challenges that teachers faced, they were the lack of computers, the weakness of the network while performing tests and interactive activities, the students 'lack of experience in dealing with these programs. The study recommended continuing to apply electronic calendar tools for their importance in e-learning. They are considered appropriate tools for evaluation in the digital age, and they can be used to avoid students interrupting direct education during crises.
\end{abstract}


Keywords: electronic evaluation, social studies, challenges.

\section{المبخص}

هدفت هذه الدر اسة النوعية إلى تشخيص و اقع تطبيق أدوات التقويم الإلكتروني في مادة الدر اسات

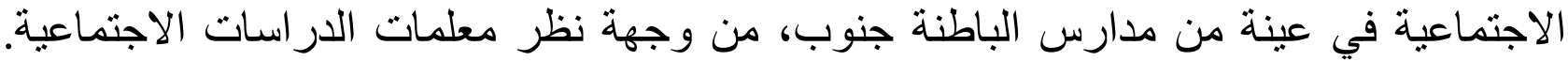

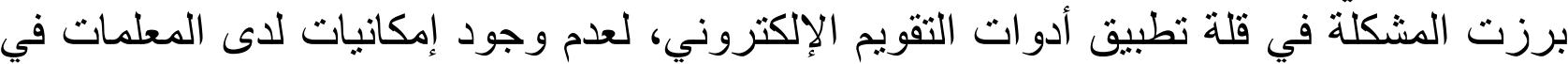
تطبيق أدوات التقويم الإلكثروني، بسبب ضنف التب البنى التحتية، التي تخص قطاع الاتصالات والثبكات. هدفت الدراسة: تشخيص أدوات التقويم الإلكتروني المطبقة، والبرامج الإلكترونية

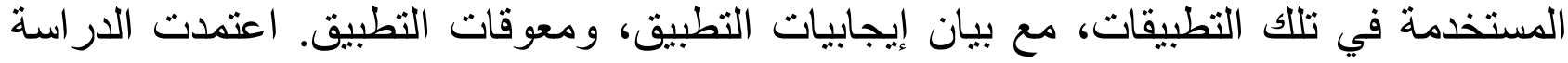

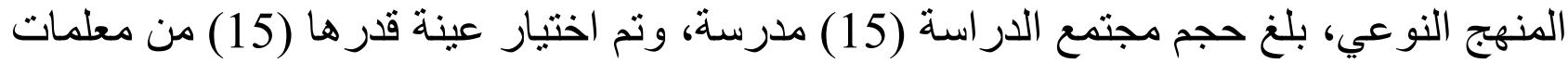

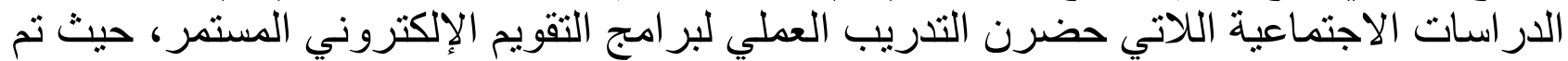
إجر اء المقابلات الفردية معهن. تم تحليل البيانات باستخدام أسلوب تحليل المحتوى. وبعد تحليل نتائج المقابلات، تم التوصل إلى النتائج الآتية: من الأدوات التي تطبقها معلمات الدات اسات

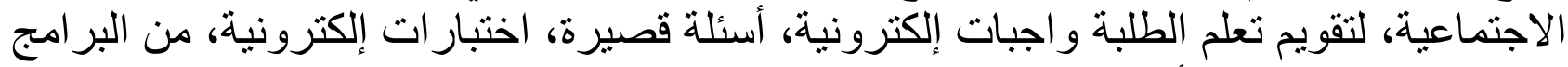
المستخدمة في تطبيق الأدوات Padelt ، Zid jard ، Google drive، الما عن إيجابيات تطبيق أدوات التقويم الإلكتروني، فقد أكدت المعلمات على رغبة الطلاب للتفاعل مع تطبيقات أدوات التقويم الإلكتروني و الحل التفاعلي، منابعة تحصيل الطلاب، التحليل الإحصائي لنتائج الطلبة

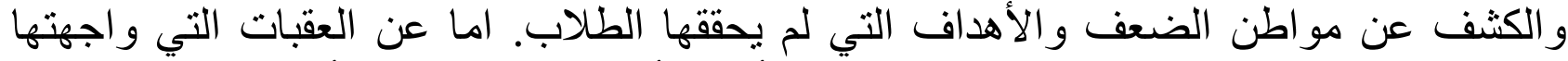
المعلمات فكانت قلة الحواسبب، وضعف الثبكة أثناء تأدية الاختبار ات و الأنشطة التفاعلية، قلة خبرة الطلاب في التعامل مع هذه البر امج،. و أوصت الدر استة بالاستمرار في تطبيق أدوات التقويم

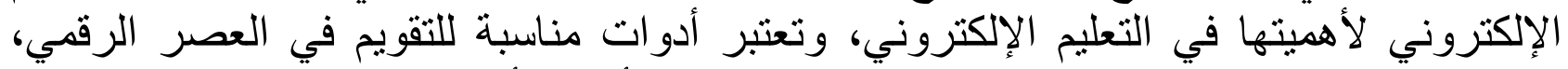
ويمكن استخدامها لتفادي انقطاع الطلبة عن التعليم المباشر أثناء الأزمات. كلمات مفتاحية: التقويم الإلكتروني، الدراسات الاجتماعية، المعوقات.

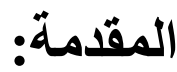

يعد التعليم عمل إنساني، يقوم به المعلم، يعلم في الطلبة، مواد علمية، و لابد أن تكون هنالك أدوات لقياس وتقويم، ما تعلمه الطلاب، ويتم تطبيق أدوات تقويم خاصة لكل مادة، منها الاختبار ات بله التحريرية، الواجبات المنزلية، الأعمال الثفوية، المشاريع، الأسئلة القصيرة، ويته ويته استخدامها فئها لمعرفة مدى فاعلية التعليم كما ذكر ها (العدري، وعيادات، 269). وذكر (2000) Wisker مفهوم التقويم التربوي كما عرفته الموسوعة العالمية للتقويم التربوي أنه عملية منهجية، يتم فيها جمع

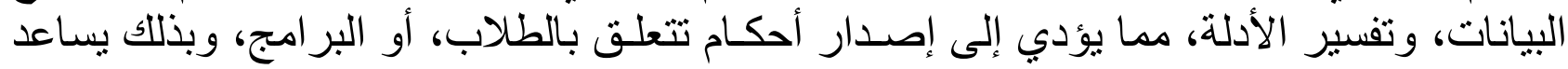

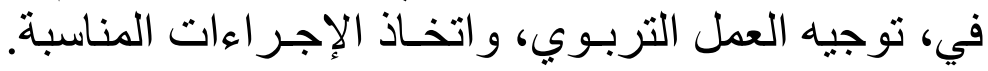

ومع التقدم التكنولوجي في كافة المجالات، ومنها المجالات التعليمية، التي و اكبت، التكنولوجيا، و التطور ات المنبثقة منه، وأكدت شامية في در استها (2018م، 2) يشهد العصر الحالي طفرة في المستحدثات التكنولوجية، إلى جانب ثورة الاتصالات، مما فرضت منطلبات لعملية التعليم و التعلم، 
مما جعل استخدام تكنولوجيا التعليم، مطلبا أساسيا، و الاستفادة من البر امج التكنولوجية وإسية وإمكانياتها،

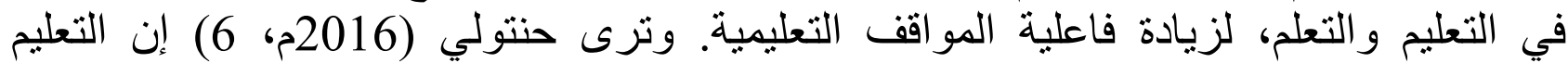

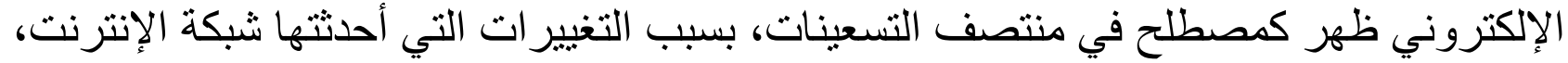

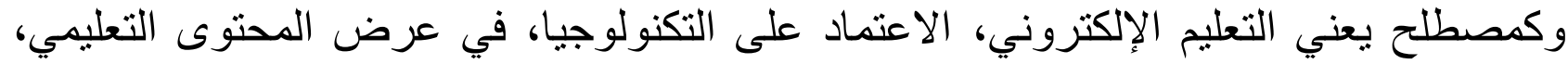

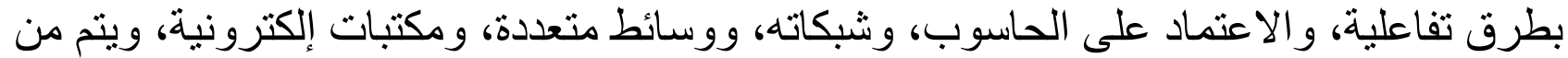

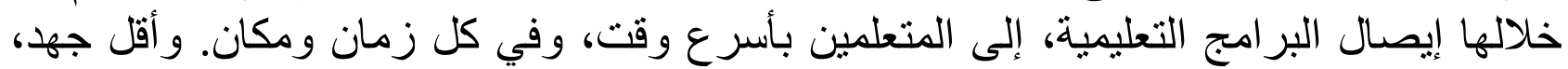
و وتكلفة.

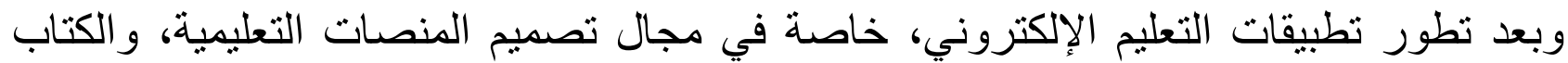

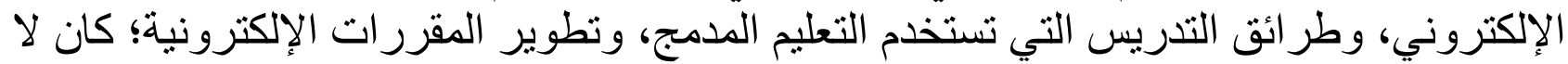

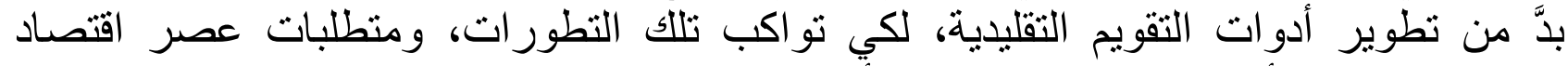

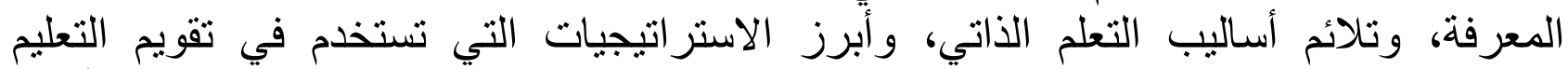

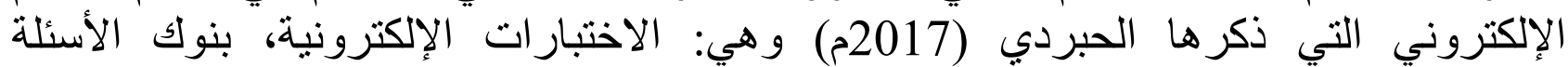

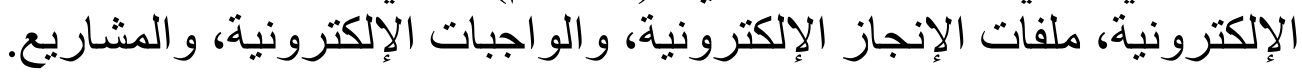

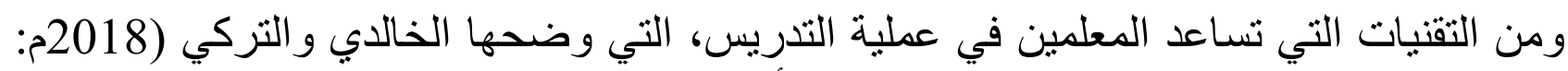

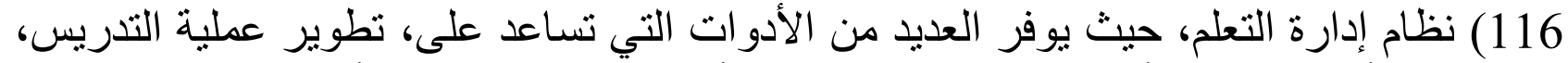

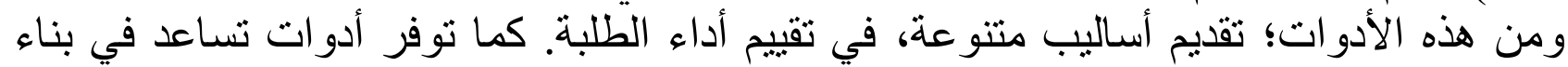

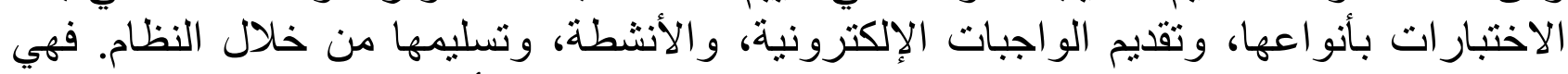

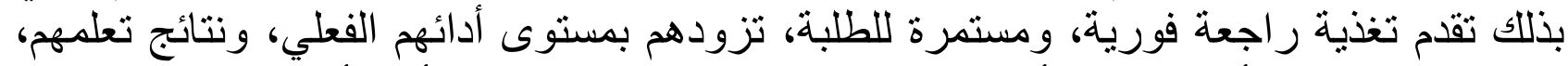

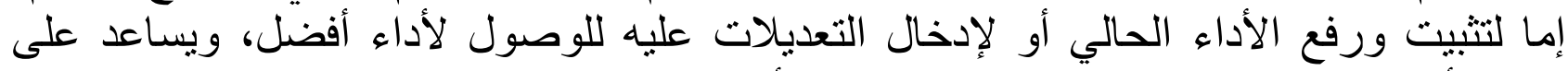

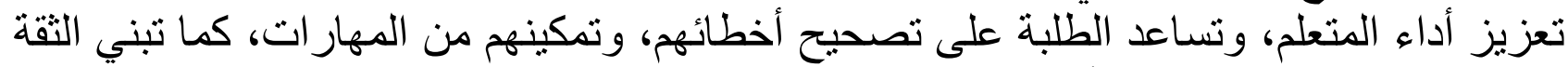

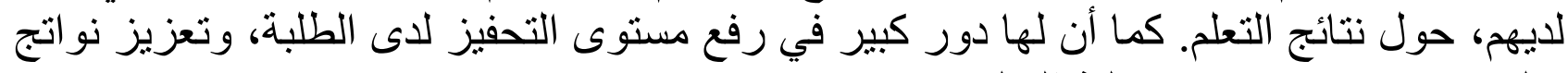
تعلمهم؛ وتسهم في تدعيم عملية التعلم.

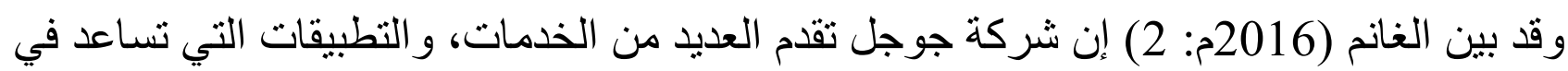

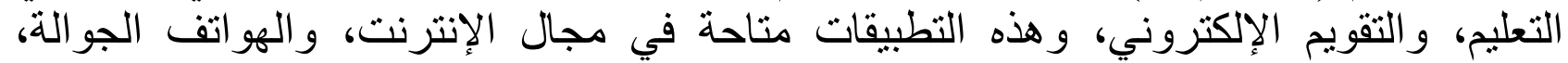

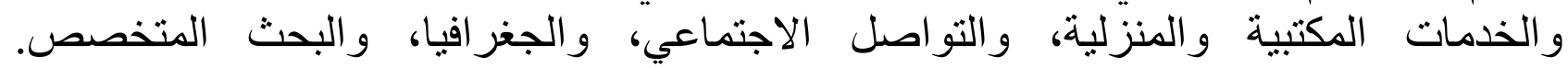

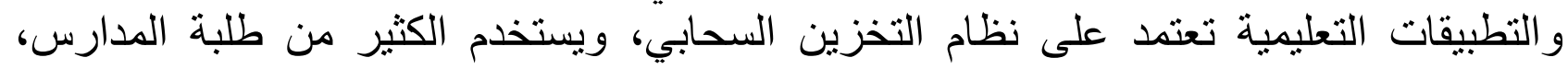

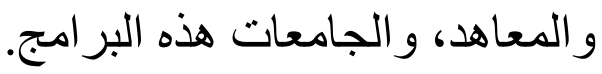

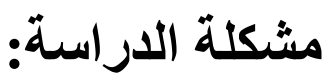
أكدت كثثر من الدراسات، على أهمية التقويم الإلكتروني، وإنه يلعب دور في التهات العملية التعليمية،

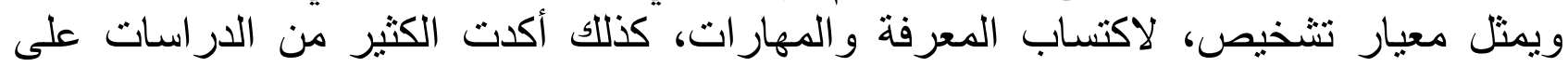

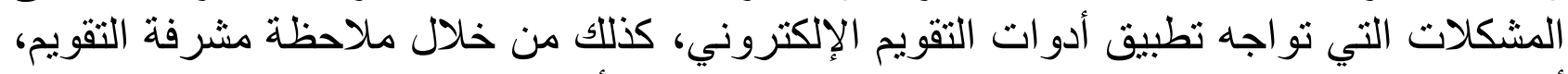

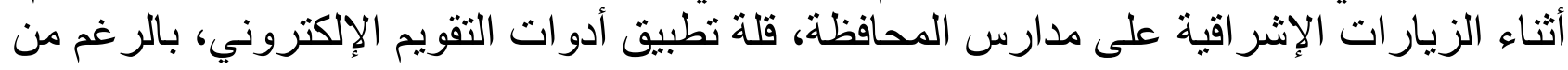

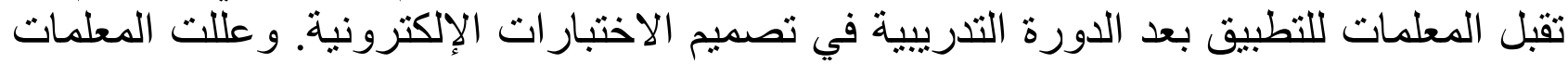

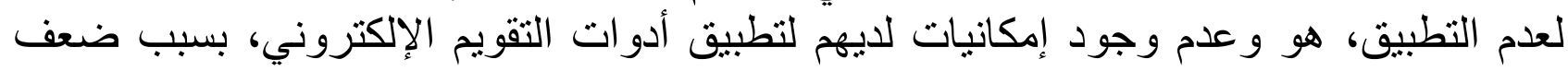

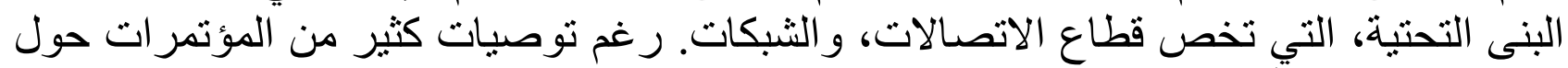

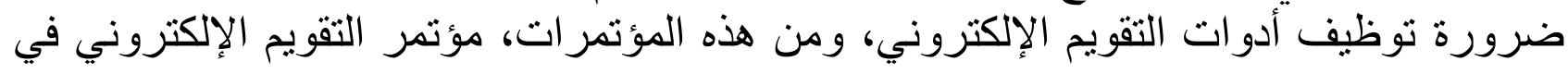


المؤسسات التعليمية، الذين عقد في القاهرة عام 2015، وجاءت توصياته بأهئ بأهية استخدام الحاسب الآلي، في القياس، و المؤتمر الدولي لتقويم التعليم 2018م، الذين الذي عقد في مدينة الرياض باض بالمملكة

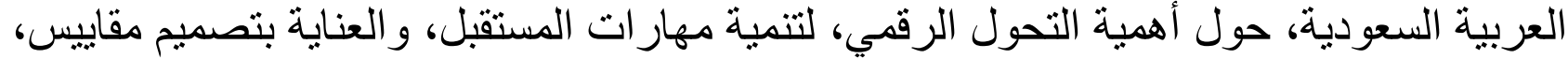

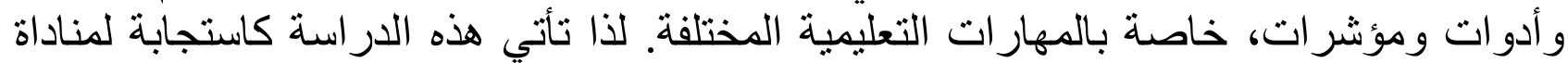
الوزارة بتطبيق التعليم الإلكتروني، وضروات وضنه ومجالاته.

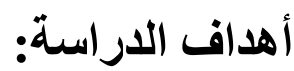

أ. تشخيص مدى تطبيق معلمات الدر اسات الاجتماعية في محافظة جنوب الباطنة للتقويم الإلكثروني.

ب. التعرف على البر امج المستخدمة في تطبيق أدوات التقويم الإكتروني، مع بيان إيجابيات التطبيق. ت. تسليط الضوء على المعوقات التي تو اجه تطبيق التقويم الإلكتروني.

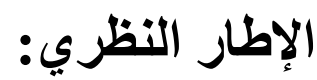

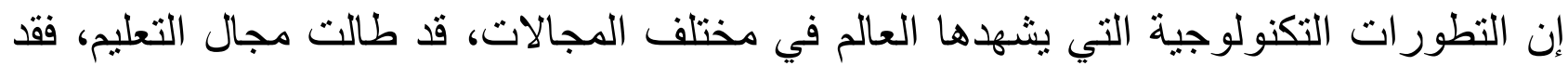

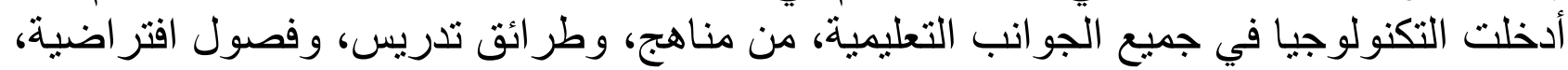

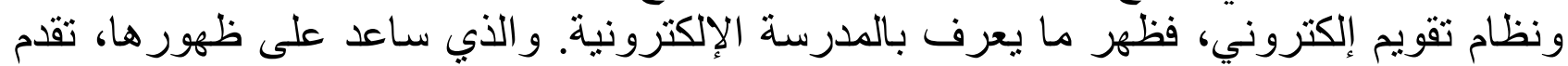

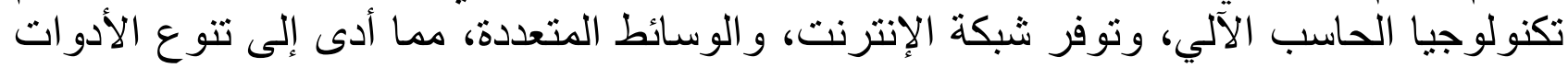

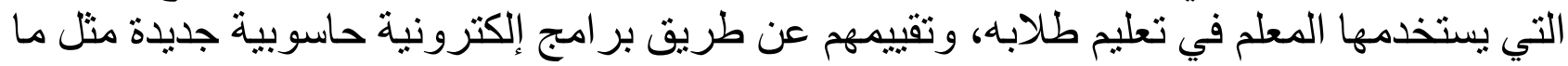
ذكر مصطفى (2017م)

التقويم الإكتروني: يعرفه العنزي (2019م، 62) هو مجموعة من الأدوات والأساليب، التي التئي

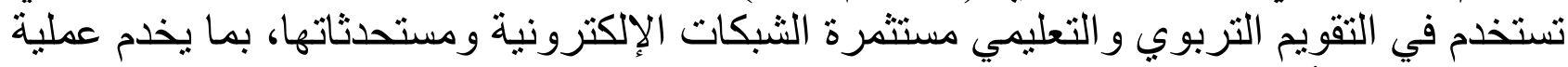

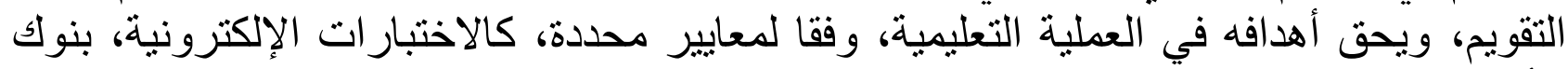

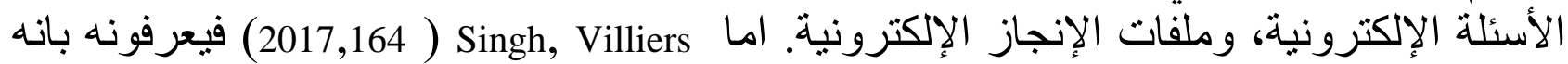

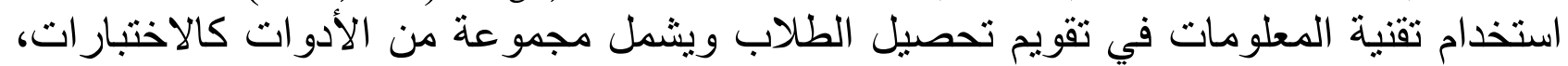

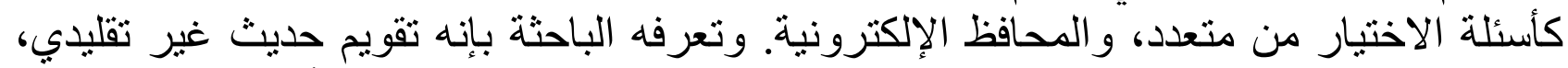

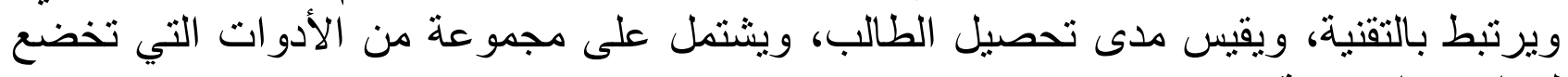
لمعايير بناء معينة.

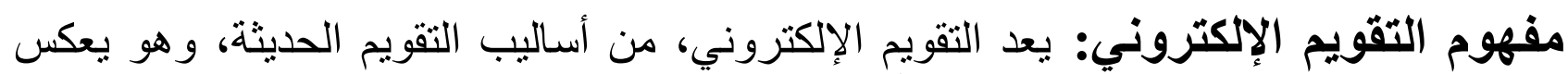

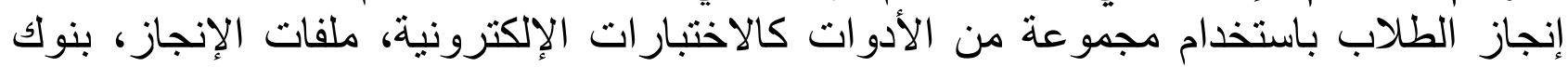

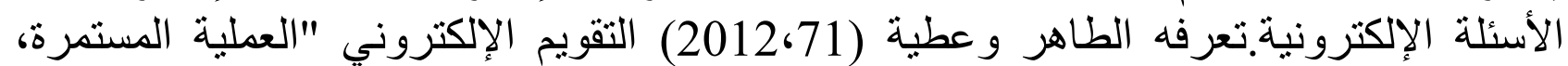
و المنتظمة التي تهدف إلى تقيميم أداء الطالب عن بهن بعد باستخدام الثنبكات الإلكترونية".

\section{فوائد التقويم الإلكتروني:}

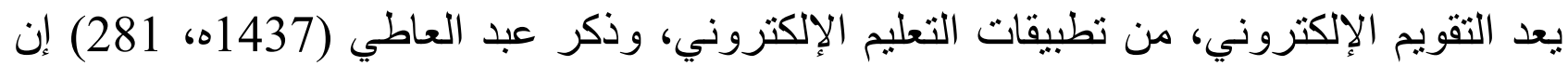

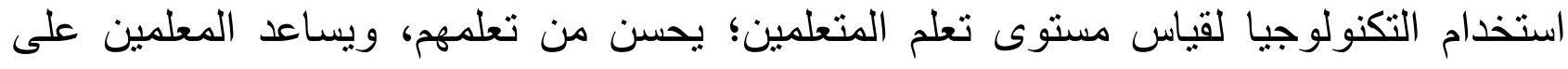




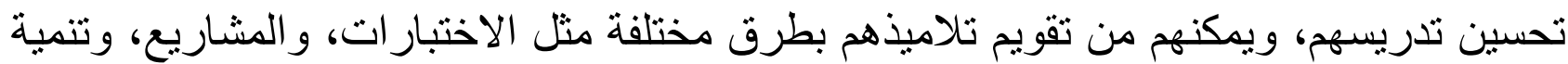

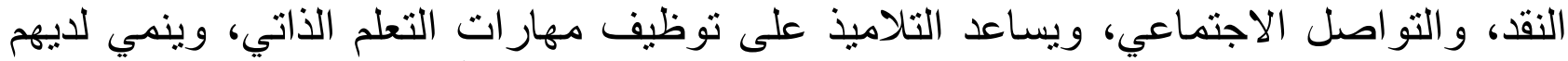

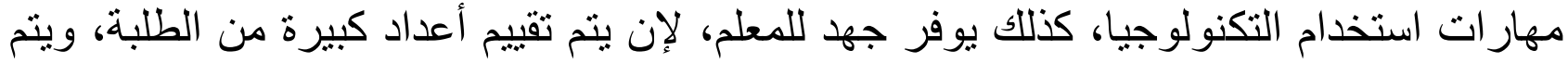

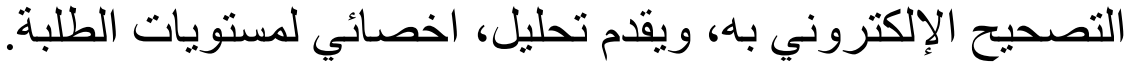

\section{أشكال التقويم الإلكتروني:}

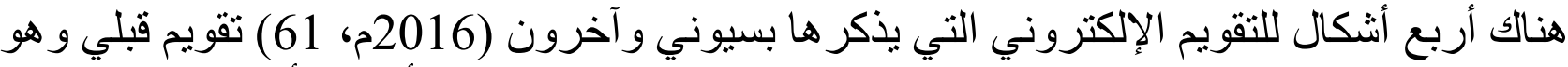

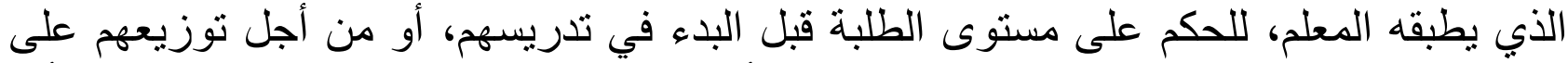

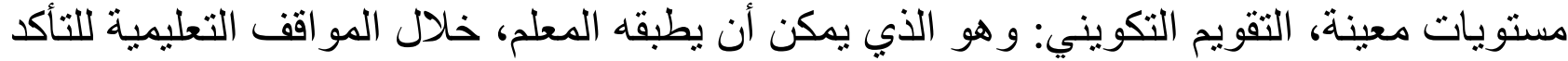

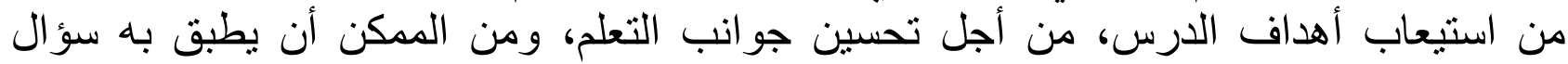

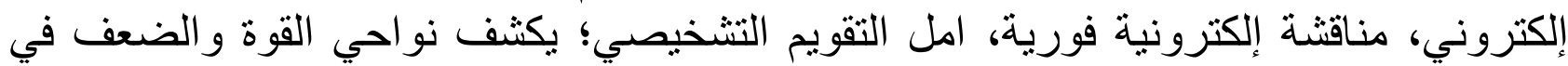

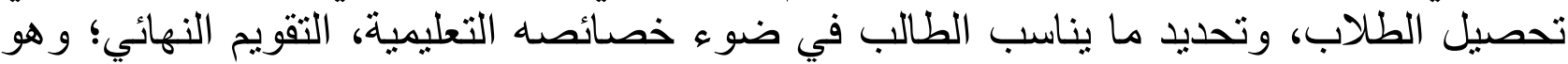

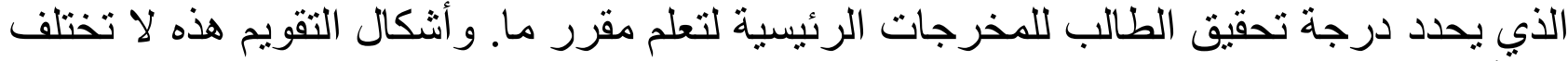
عن أشكال التقويم التقليدية، ولكن الاختلاف في بيئة التعلم.

\section{أدوات التقويم الإلكتروني التي يطبقها المعلم لتقييم طلابه:}

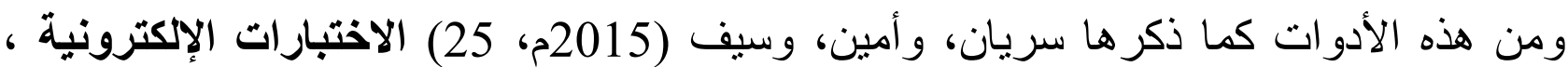

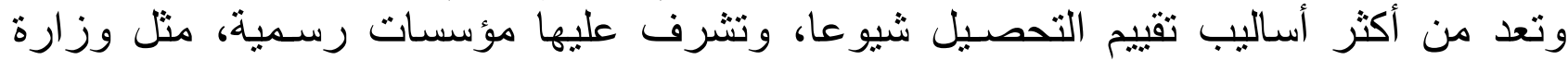

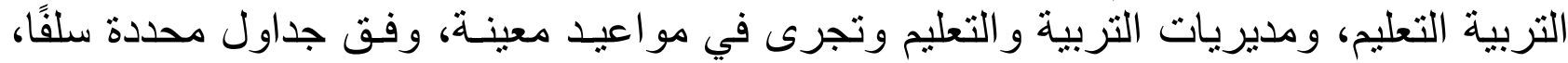

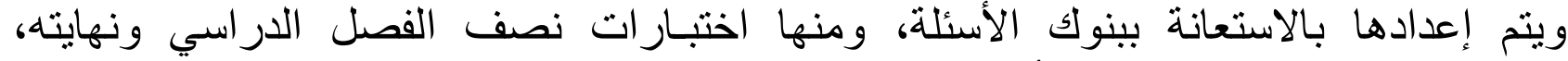

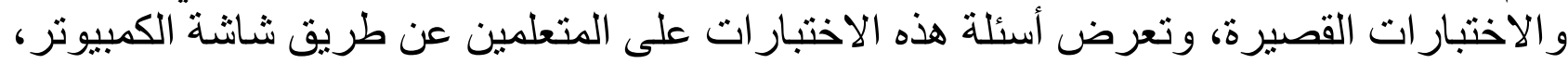

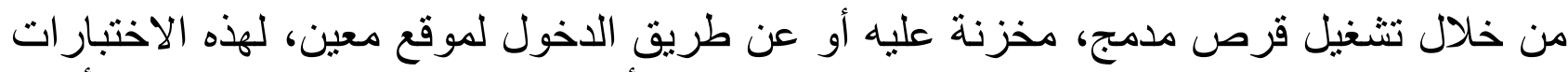

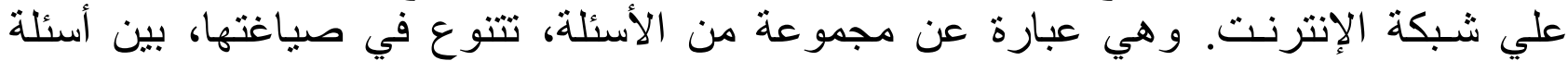

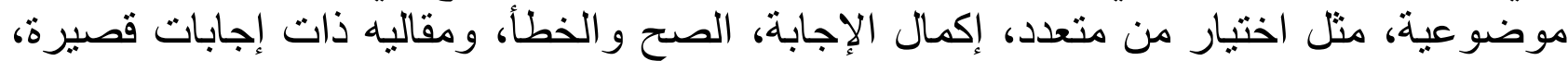

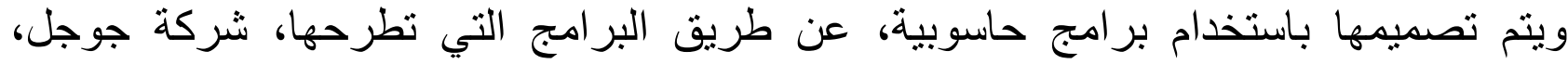

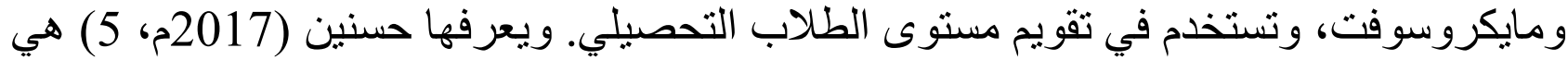
اختبار ات تقدم للطلبة عبر البر امج الحاسوبية، ويتم بناؤها وتصحيحها عبر هذه البرمجيات.

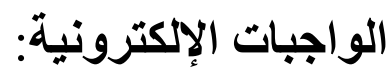

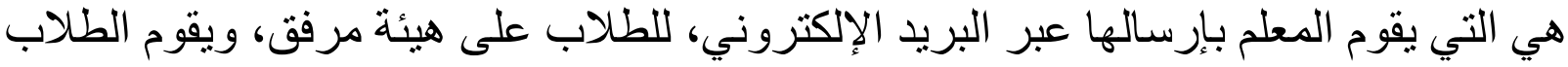

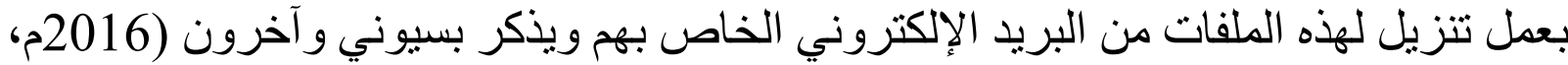

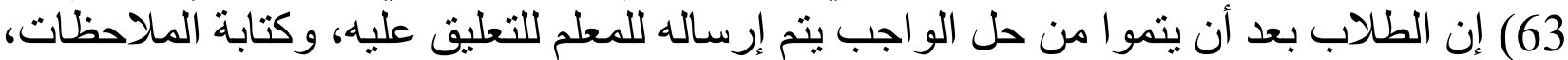

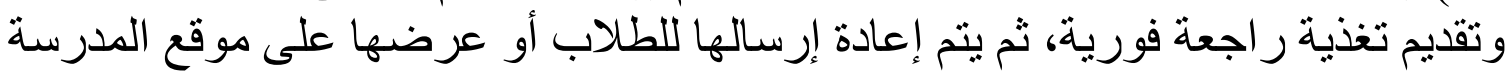
الإلكتروني.

\section{البرامج المستخدمة في تطبيق أدوات التقويم الإكتروني:}

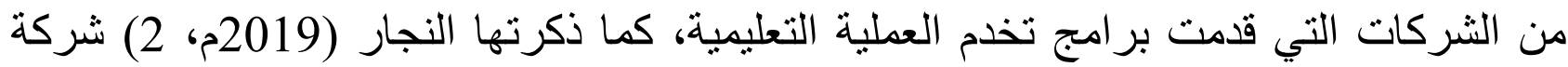

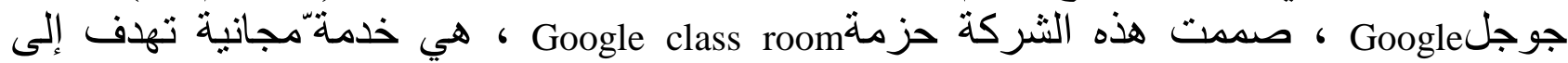
تبسيط إنشاء المهام مجانية على الويب، وتم تطوير ها بواسطة جوجل للمدارس، وتم وتوزيعها، 
وتصنيفها، بطريقة غير ورقية. والغرض الأساسي من جوجل كلاس روم هو تبسيط عملية

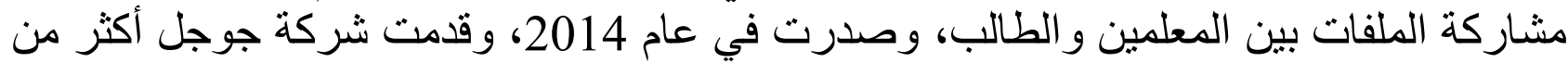

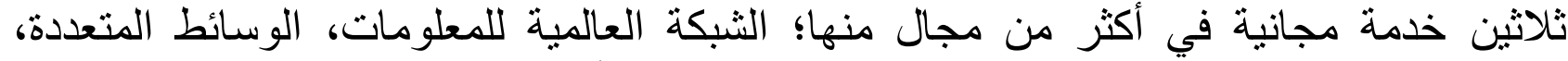

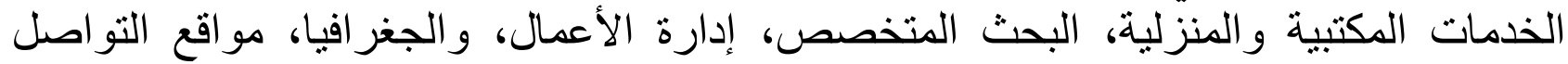

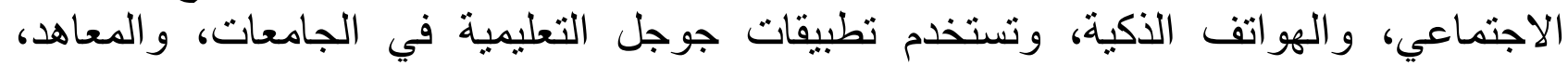

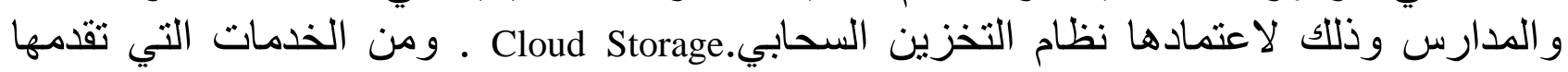

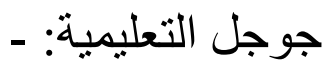

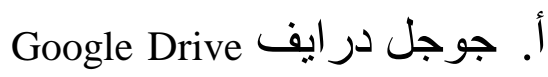

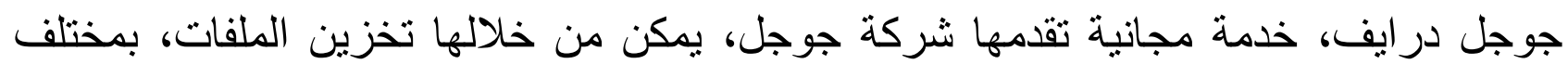

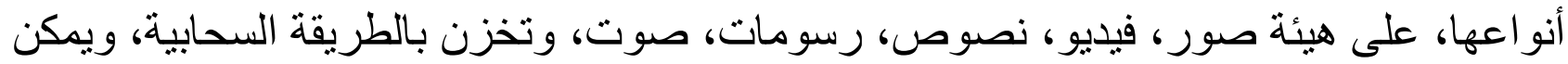

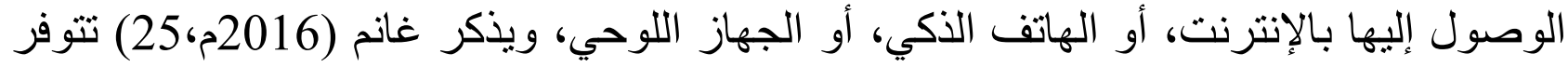

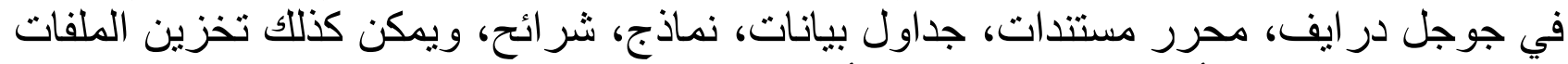

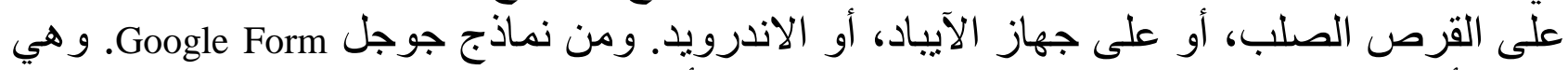

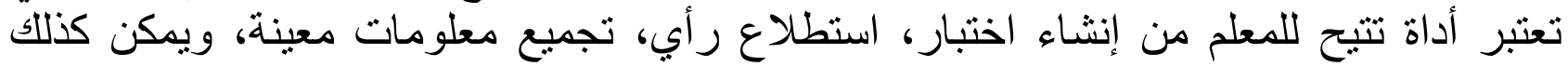

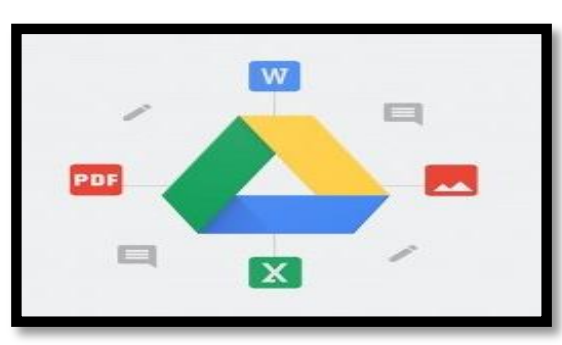
تحليل النتائج.

خدمة التخزين السحابية في جوجل درايف

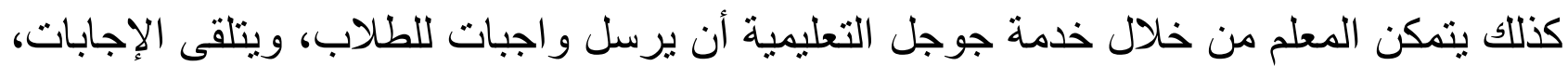

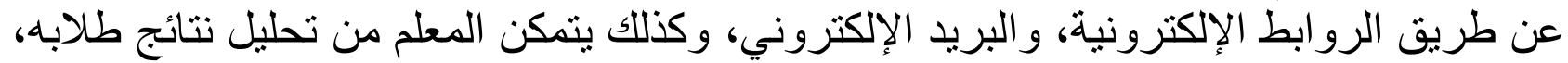

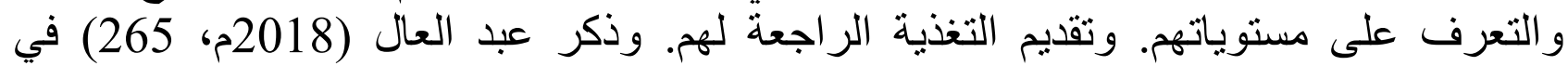

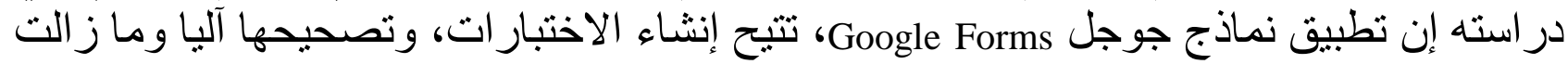

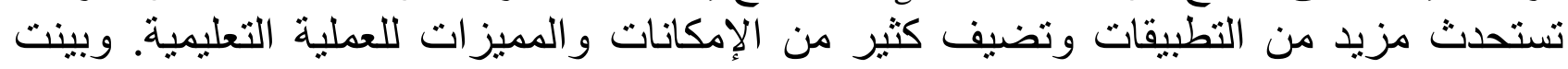

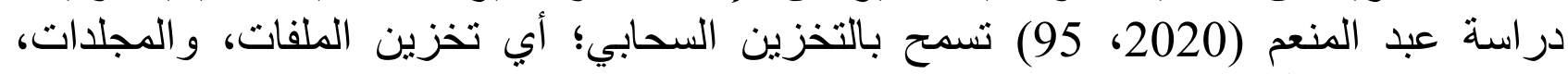

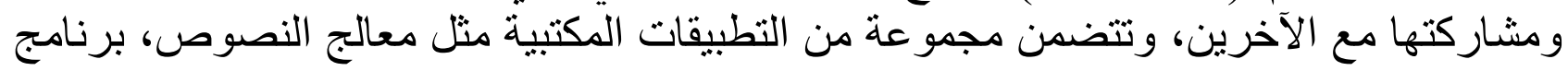

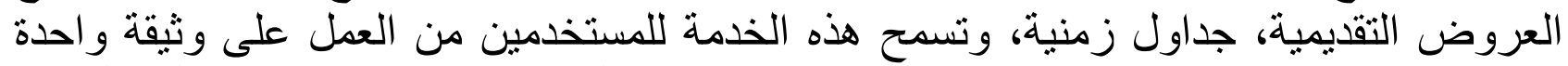

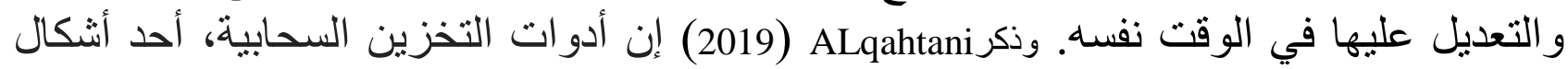

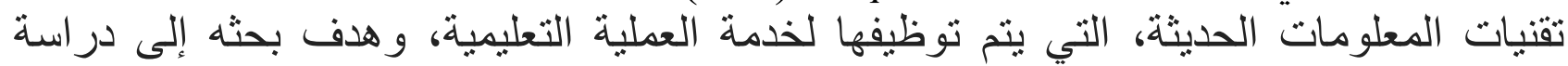

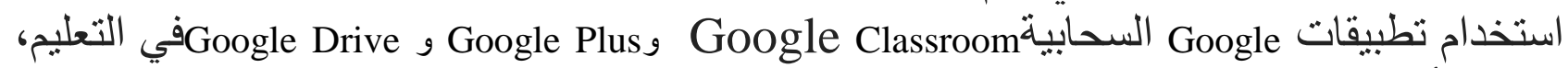

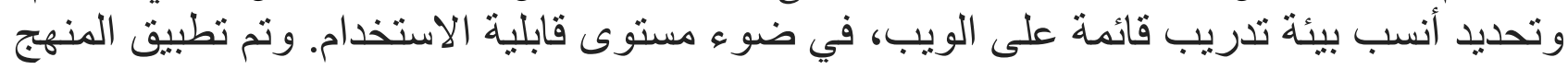

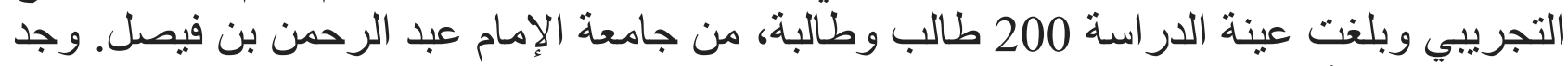

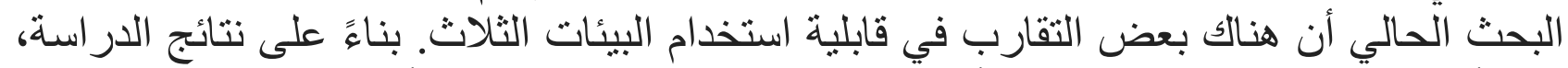

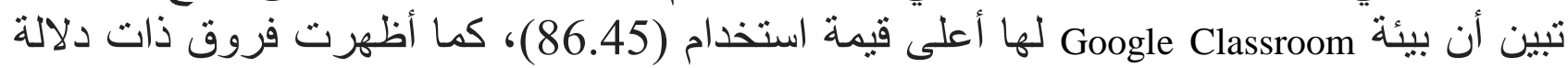


إحصائية في التحصيل الدراسي في تطبيق خدمة Google Classroom في العملية التعليمية.اما

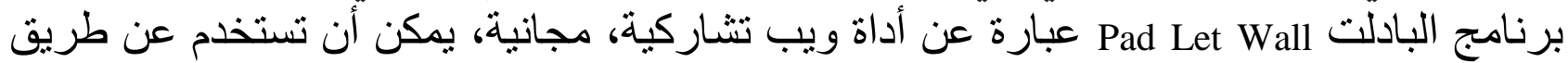

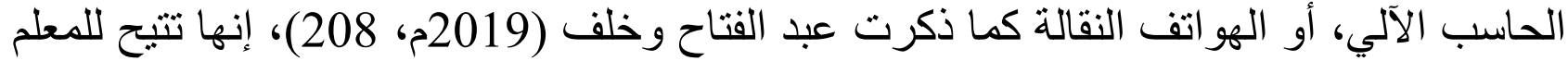

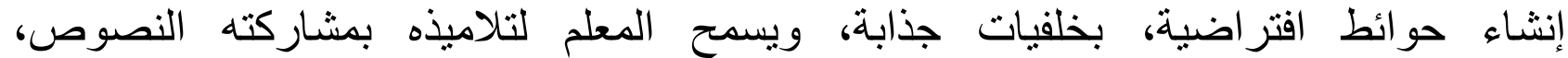

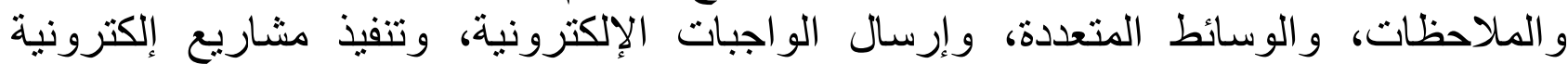

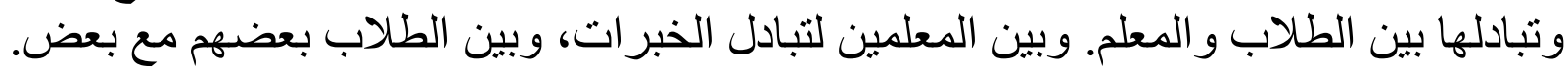

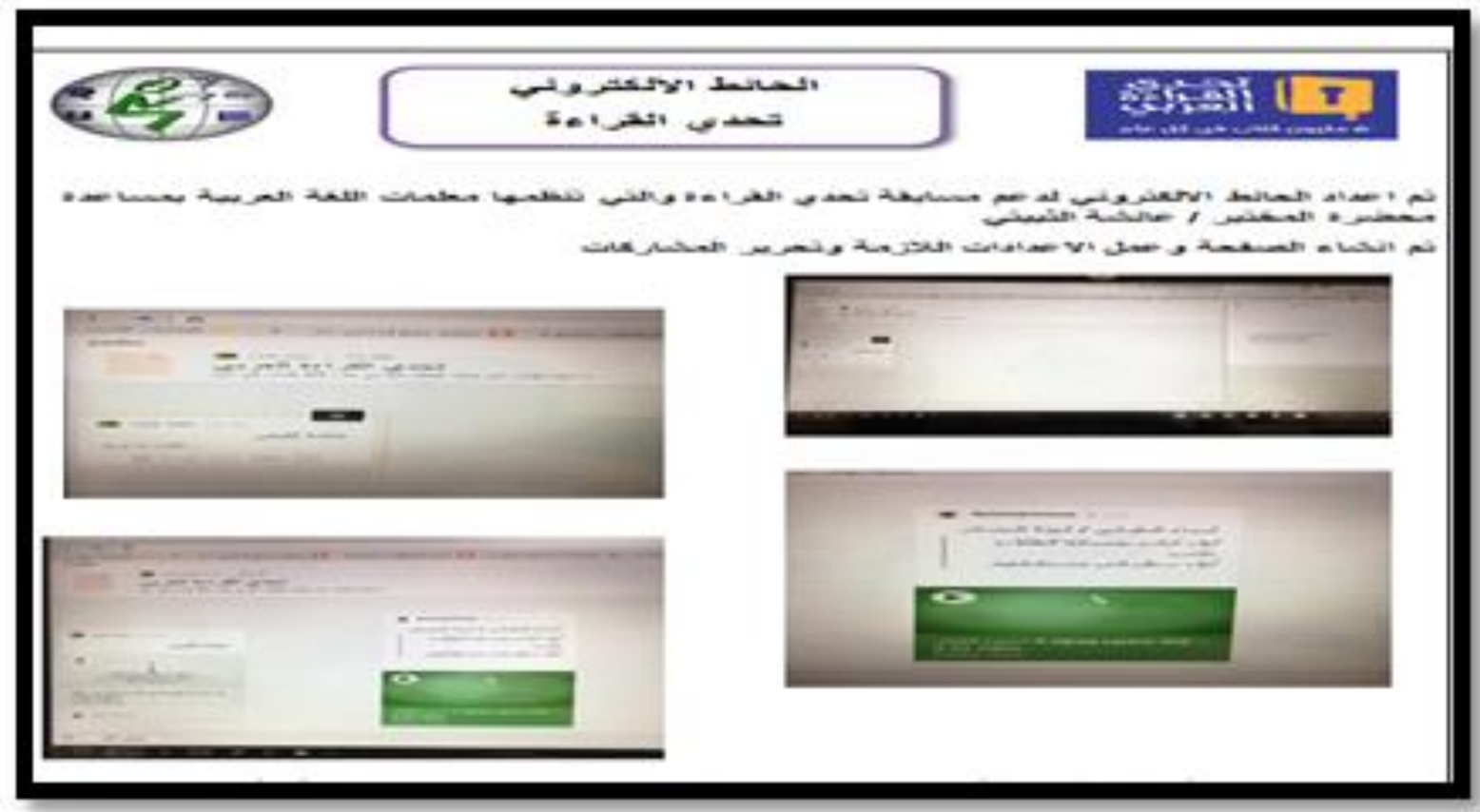

الارراسات السابقة

استهدفت در اسة العنزي (2019م، 59) التعرف على درجة ممارسة معلمي الدر اسات الاجتماعية

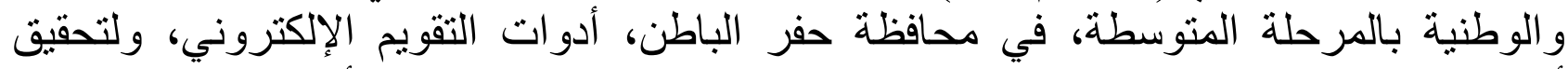

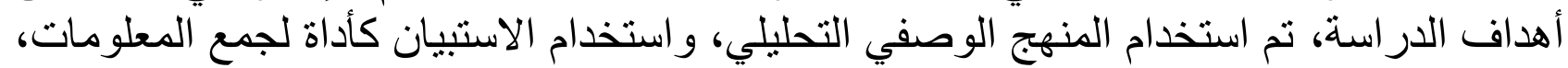

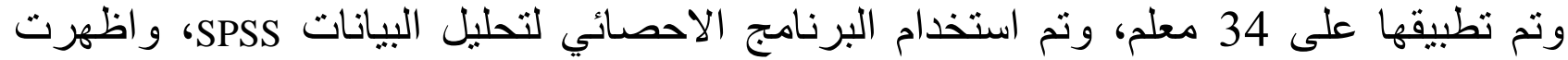

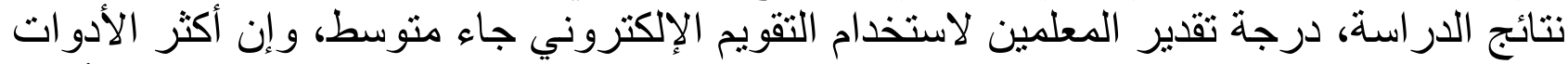

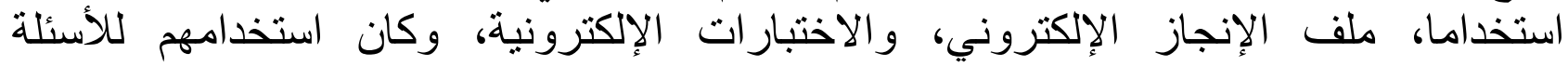

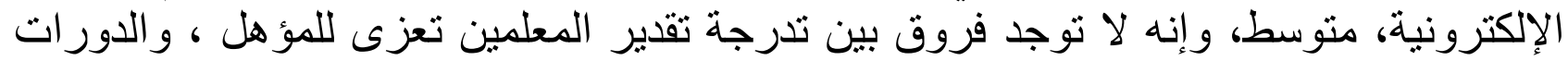

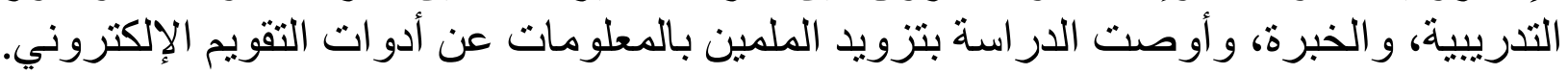

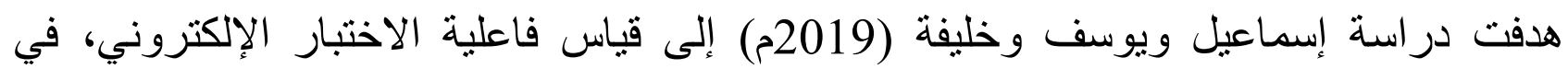

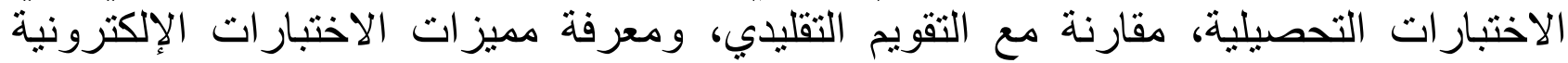

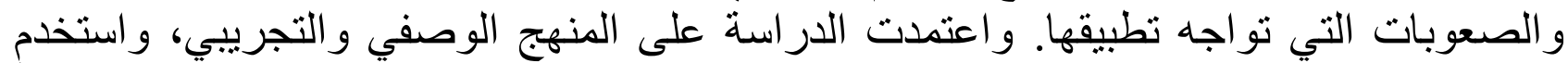

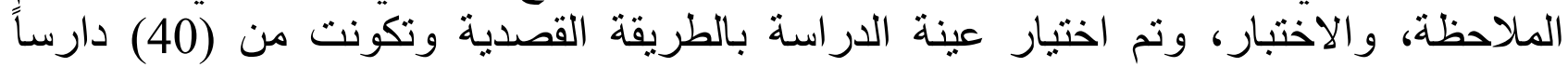

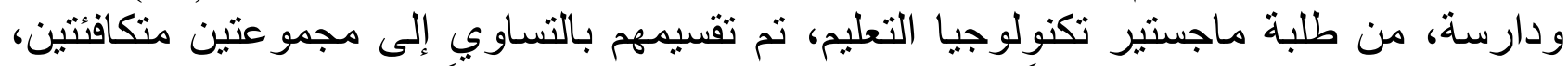

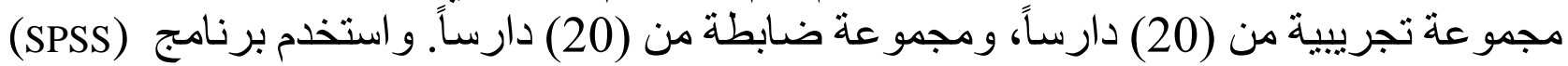

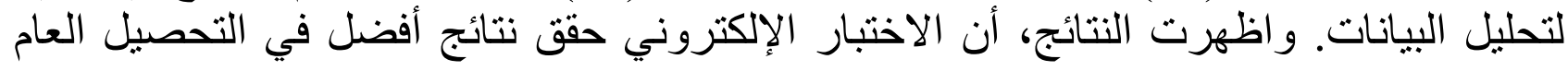


عند مستوى الدلالة الإحصائي (0.05)، وكذللك حقق أفضلية في مستويات التذكر ، الفهم، و التحليل

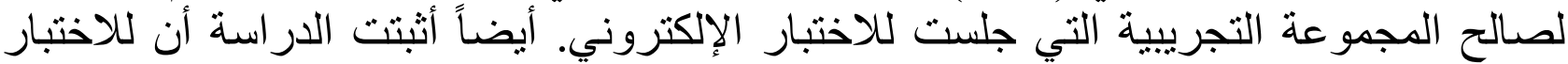

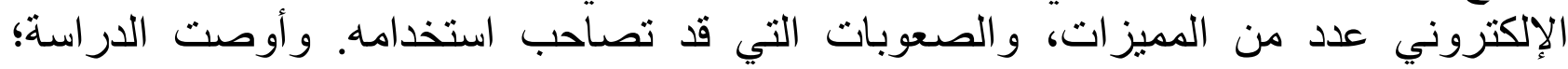
بتوظيف الاختبار ات الإلكترونية، في المؤسسات التعليمية المختلفة، وقياس فاعليتها في عملية التقويح.

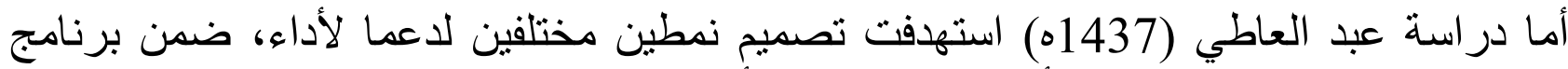

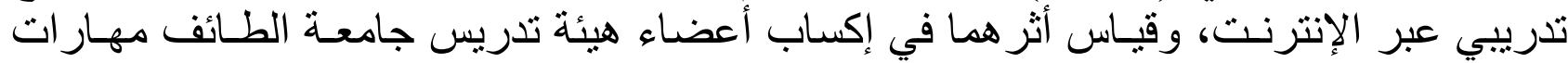

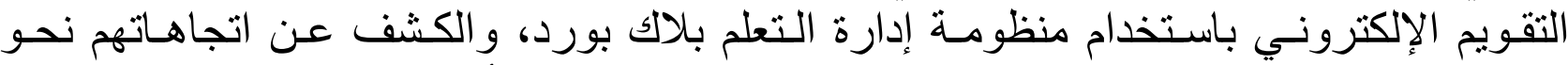

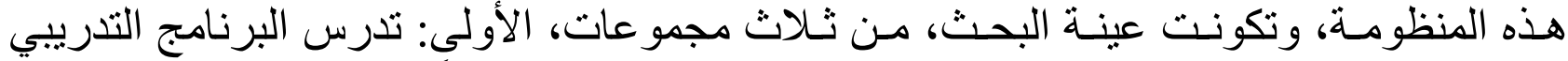

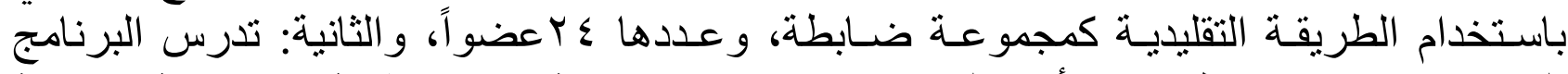

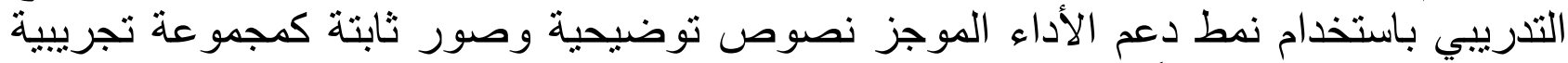

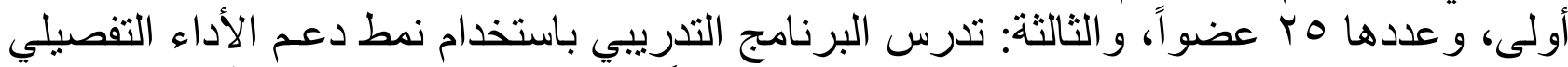

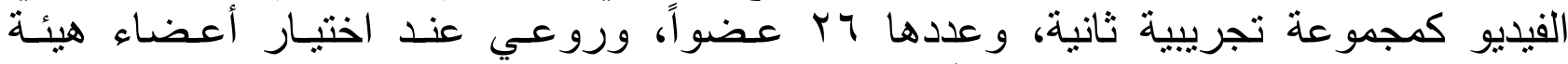

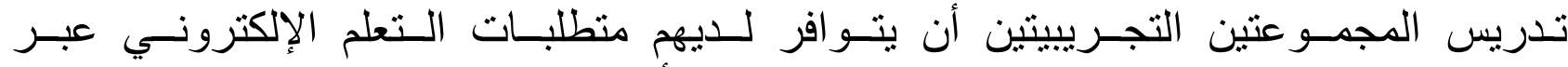

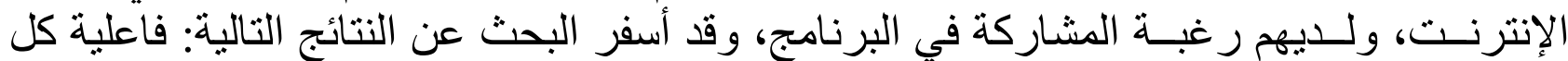

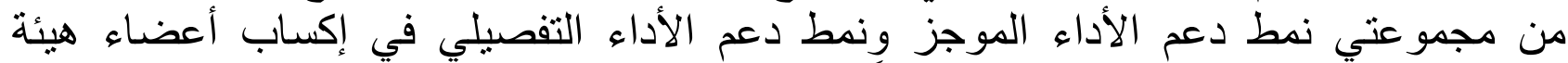

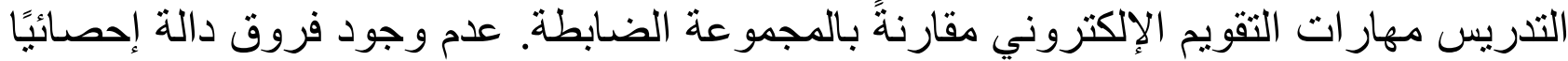

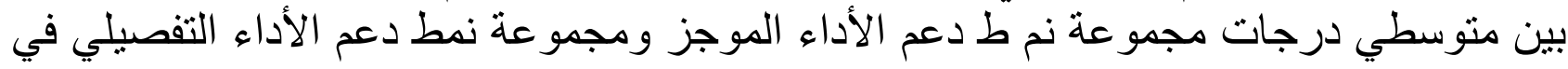

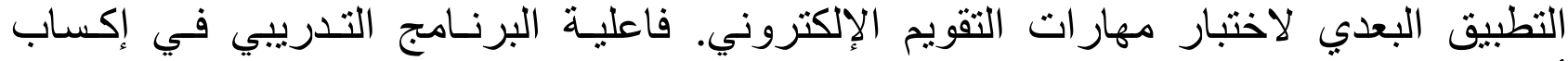

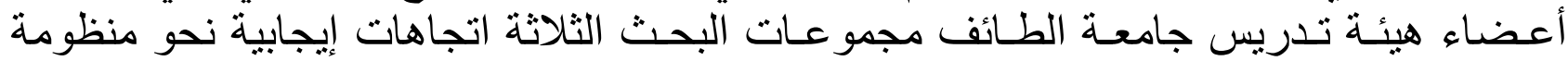

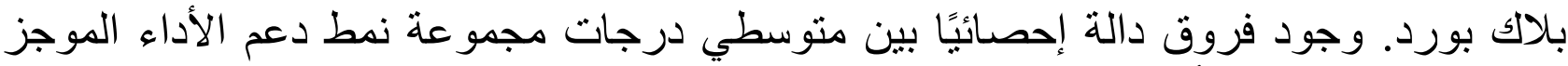

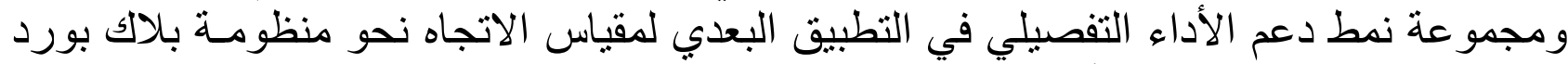
لصالح مجموعـة نمط دعم الأداء التفصيلي.

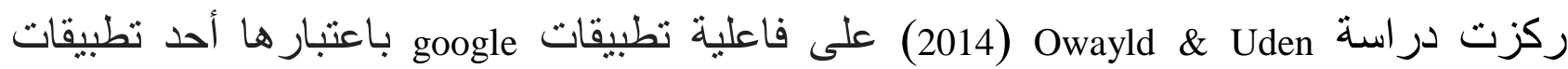

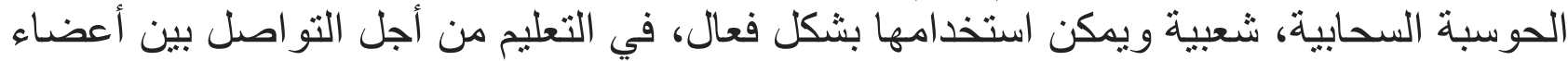

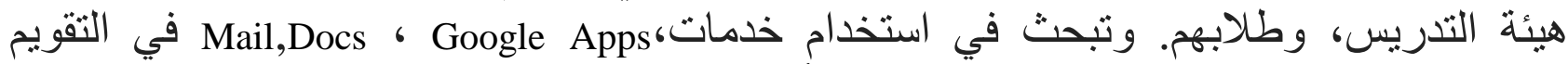

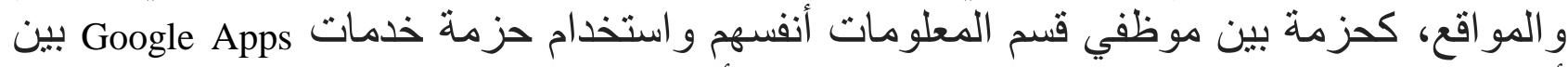

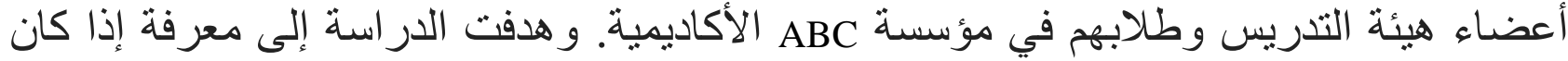

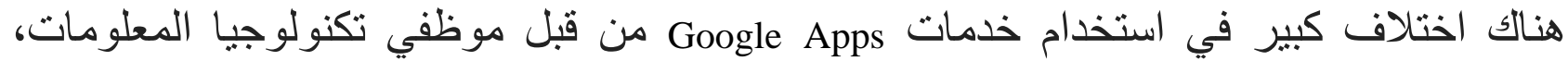

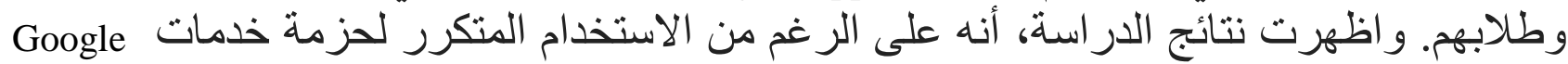
Apps

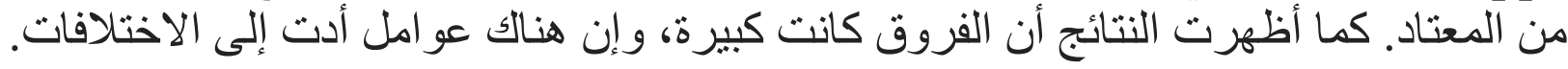

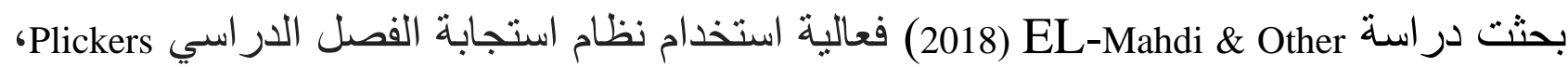

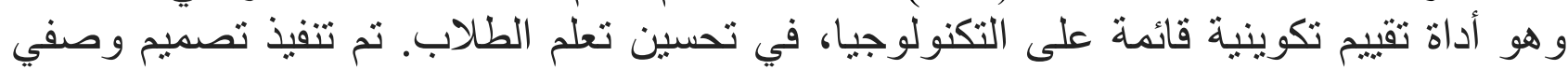

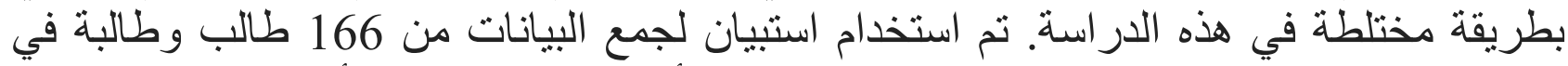

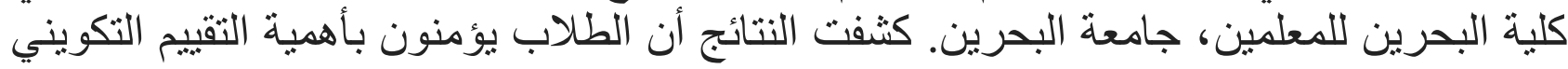


وتلقي ردود الفعل الفورية التي يدعمها استخدام . Plickers علاوة على ذللك، أظهرت النتائج أن

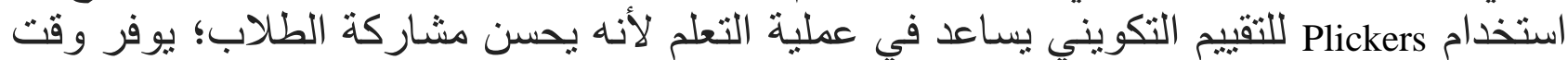

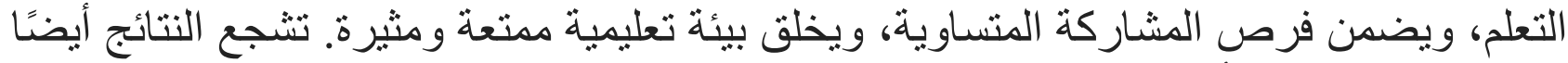

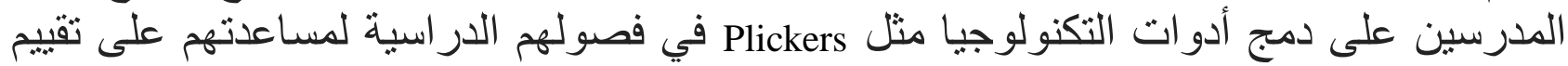
فعالية تعليههم وتعلم طلابهر.

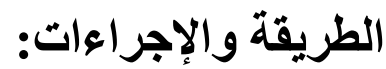

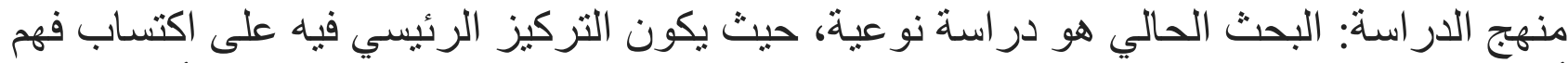

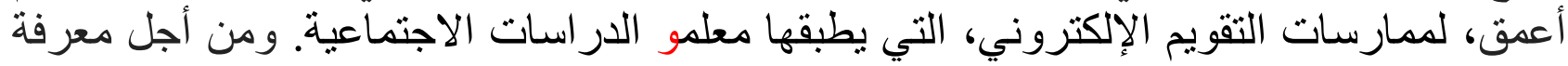

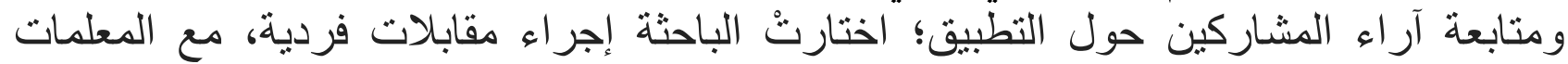

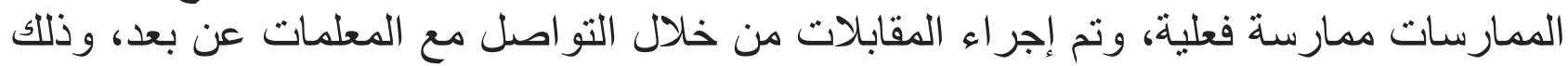
بسبب جائحة كورونا التي تز امنت مع فترة التطبيق، وتضمنت أسئلة المقابلة شبه المفتوحة المبات الآتي: أ. اذكر أدوات التقويم الإلكتروني التي استخدمتها في تقويم طلابك. ب.ما الأداة الأكثر استخداما من قبلك في التقويم الإلكتروني للطلاب؟ وما مميز اتها؟ ت.ما المعوقات التي تواجهلك عند تطبيق أدوات التقويم الإلكتروني؟

\section{المشاركون في عينة البحث:}

تكون مجتمع الدر اسة من المعلمات الأو ائل مادة الدراسات الاجتماتهاعية، في (15) مدرسة بمحافظة

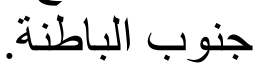

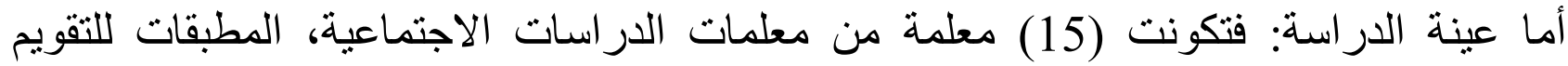

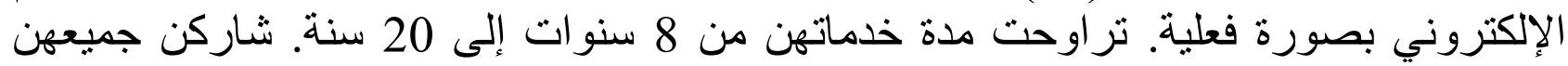
بلدورة واحدة أو أكثر من الدور فلة ترات الآتية:

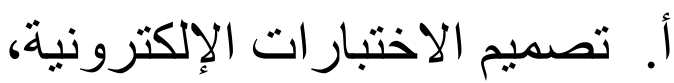

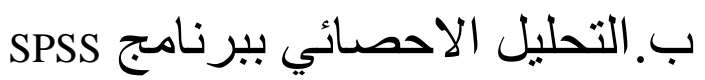
ت.دورة تطبيقات جوجل التعليمية، ث.دورة ما مبكروسوفت

ج. دورة انتل، ح. تصميم الاستبانات الإلكترونية، خ. تقنية الهول جرام د. دورة تطبيقات جوجل التعليمية، ذ. دورة ما ميكروسوفت 
أعدتْ الباحثة أداة لمعرفة تطبيق المعلمات الأوائل لمادة الدراسات الاجتماعية، لأدوات التقويم

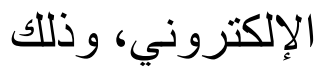

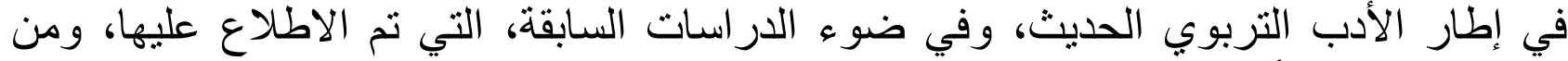

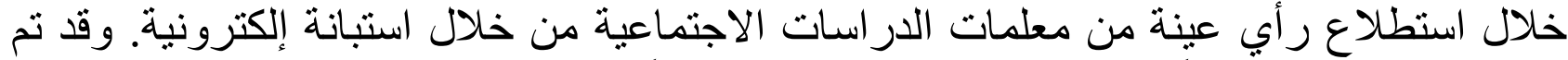

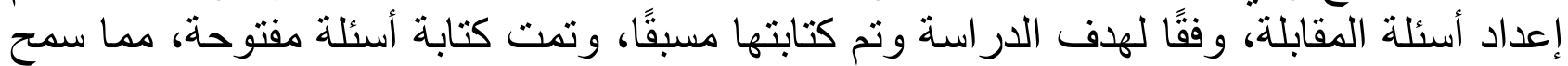
بتطوير الإجابات عبر أسئلة المتابعة.

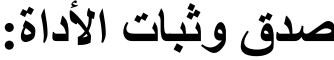

تمت مر اجعة الأسئلة عدة مر ات وفحصها من قبل مختصين في التقويم التربوب، حيث قادئ وامو ا بإبداء

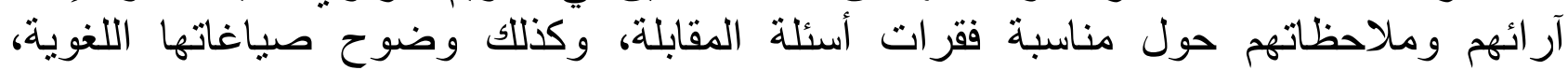

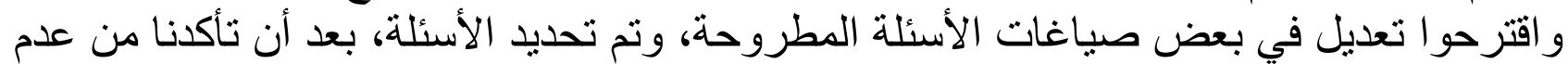

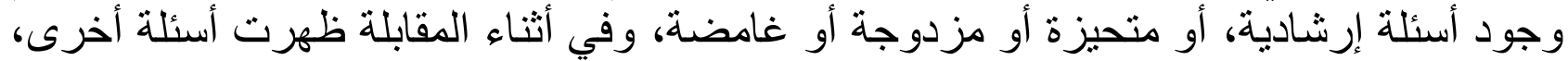

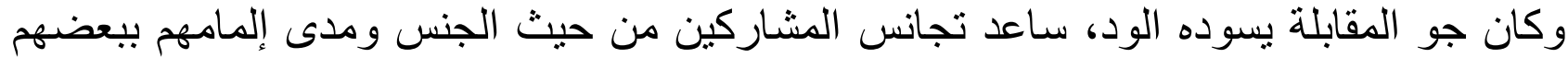

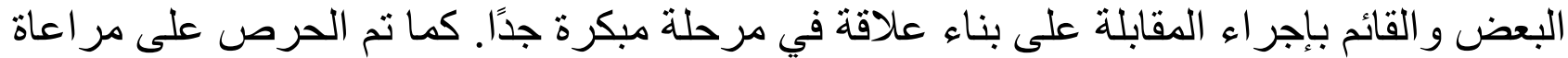

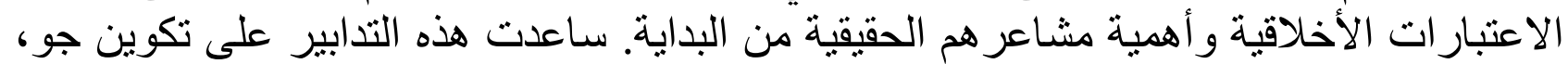

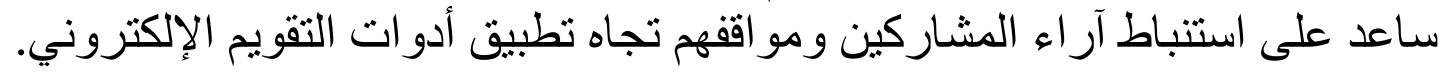

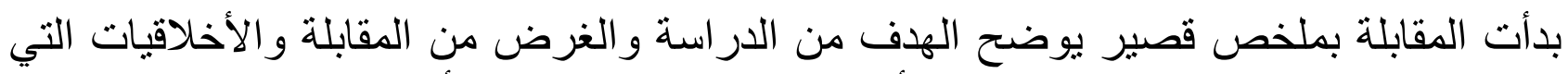

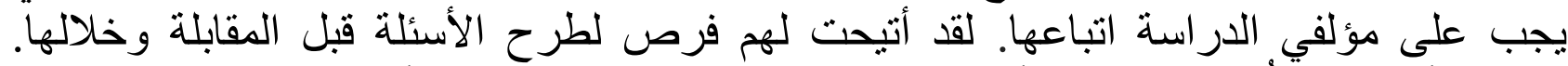

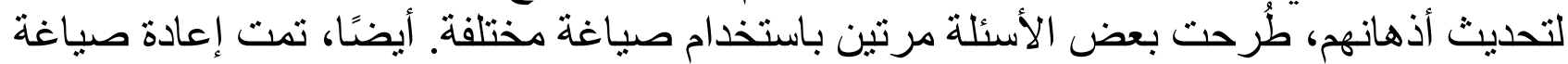

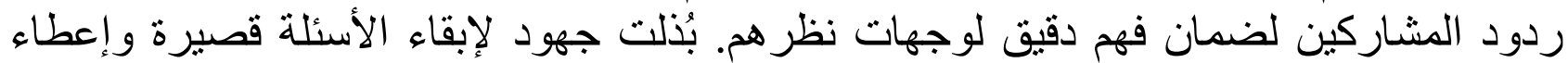

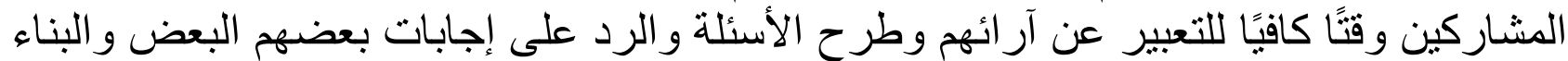

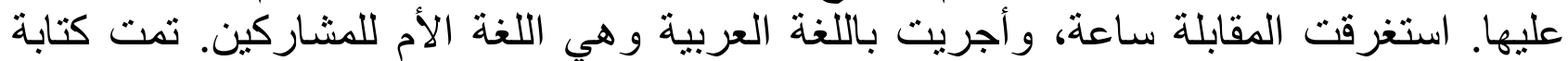

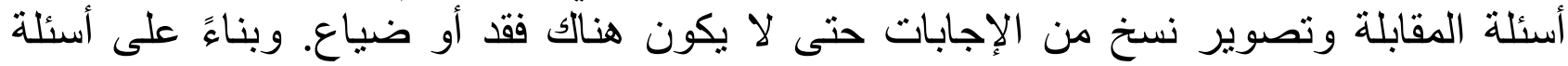
البحث، وتحليل البيانات وتفسير البيانات. تم إجر اء محاو لات لتجنب التفسيرات التئن المتحيزة للبيانات والالنز ام بوجهات ونظر البيات المعلمات

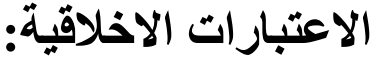

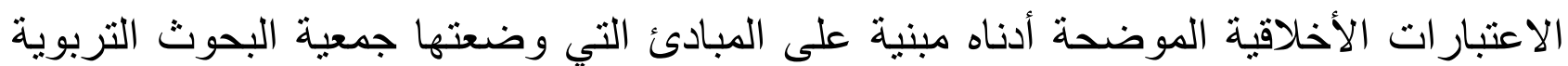

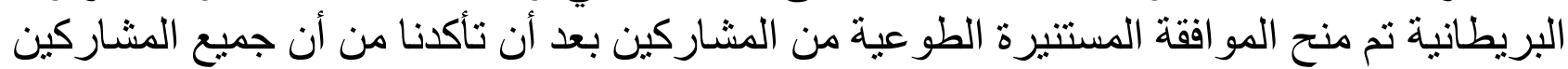

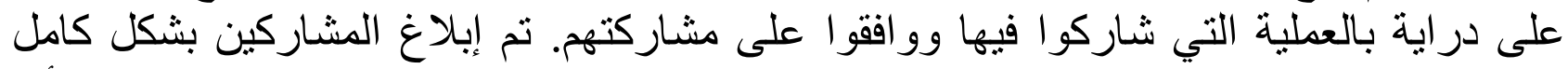

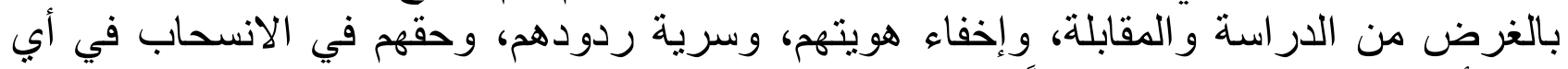

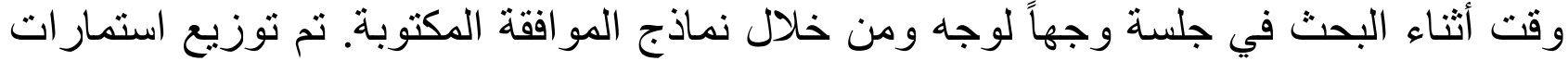

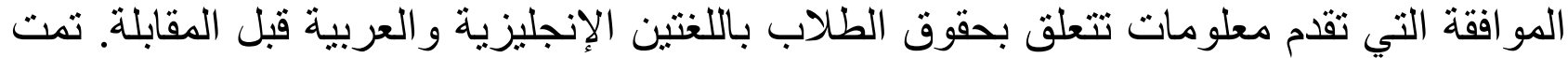

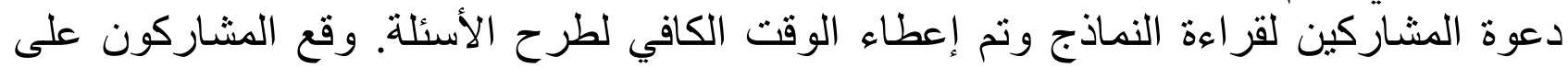

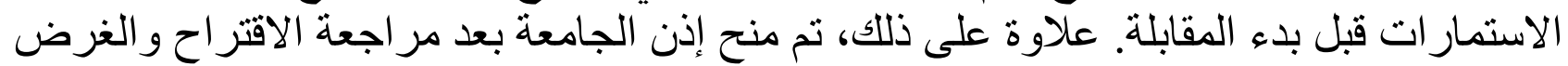

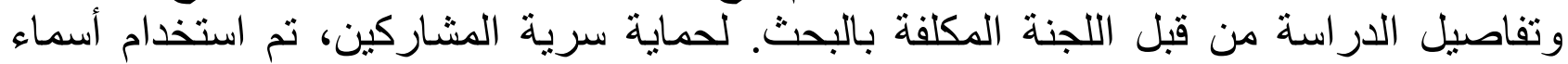
مستعارة في هذه الدر اسة. 


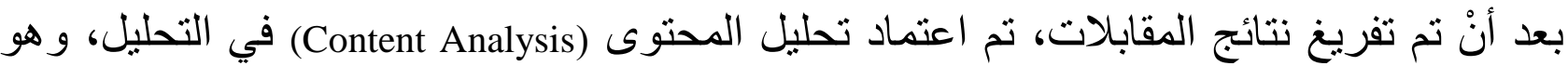

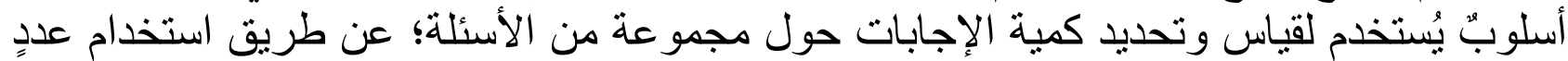

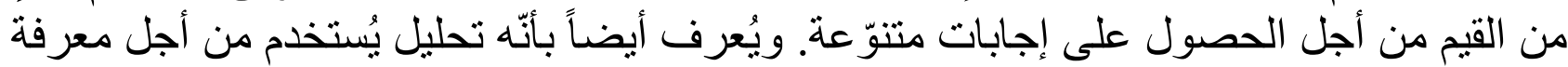

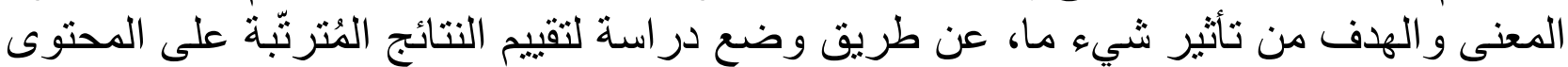

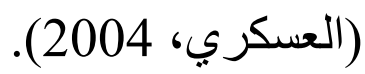

نتائج الاراسة:

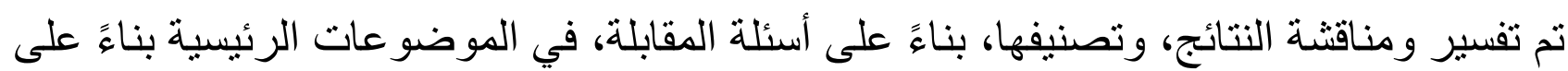

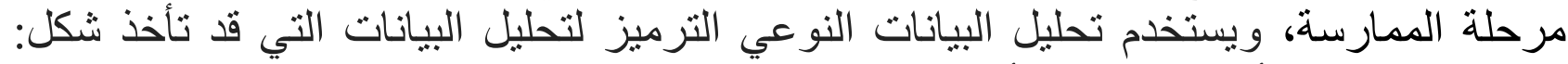

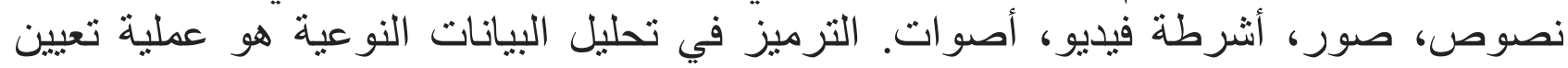

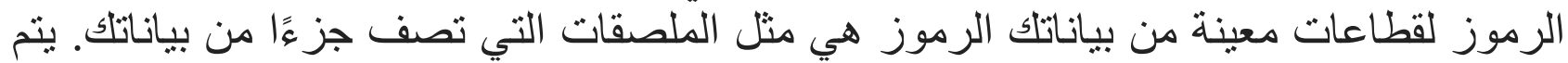

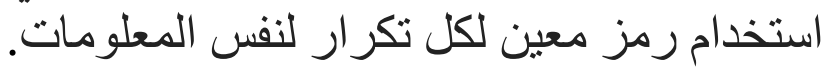

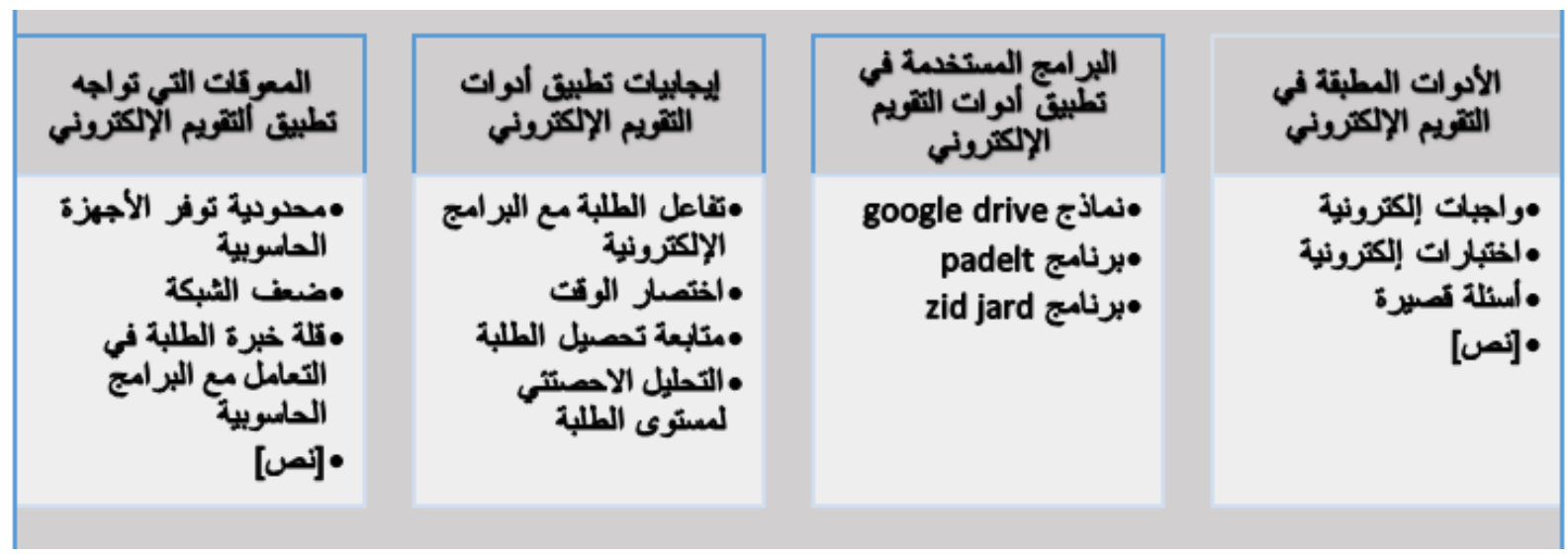

فيما يأتي عرض بأسئلة المقابلة، مع عرض إجابات المشاركين:

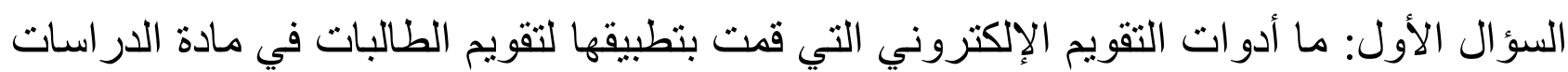

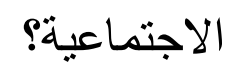

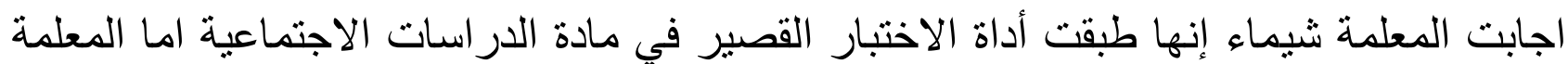

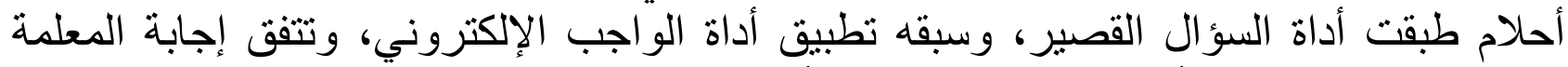

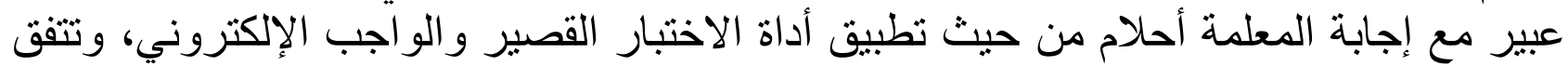

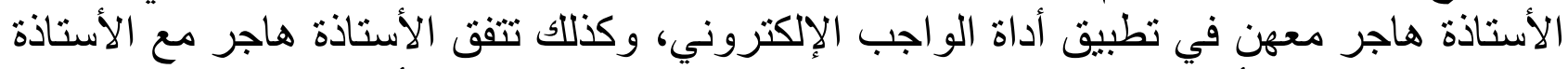

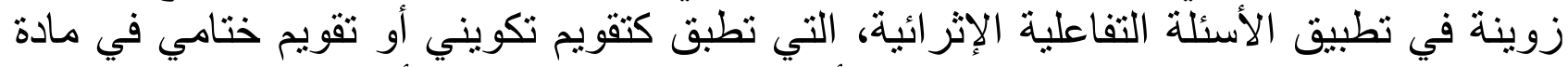

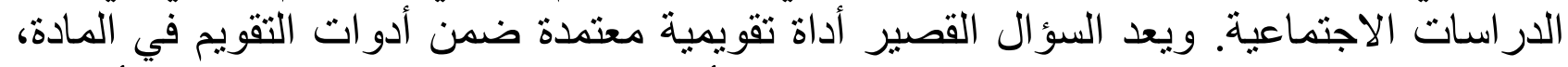

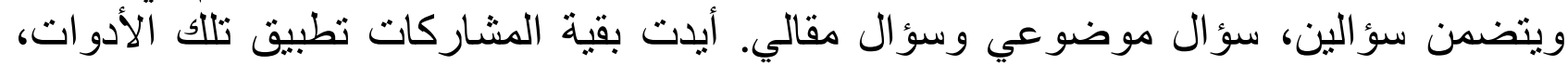
وذللك لضعف الثبكة، ونقص النصو الحو اسيب.

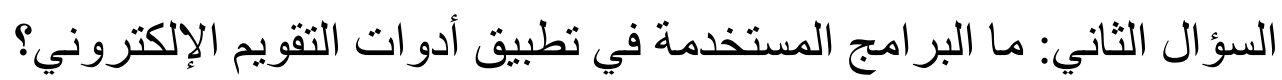

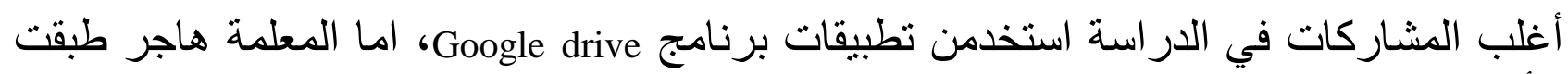

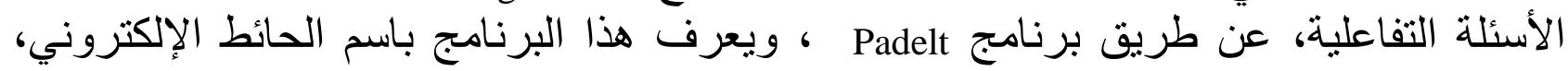




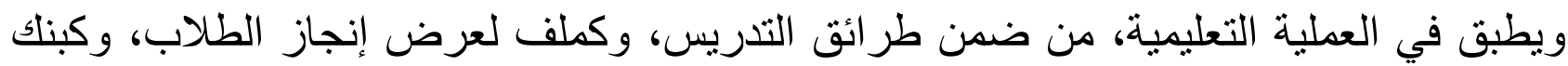

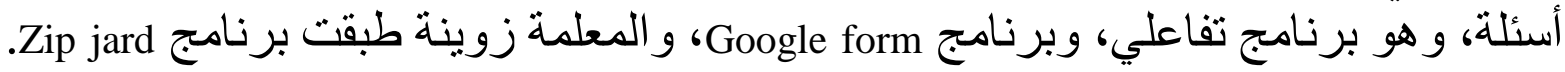
السؤال التالي: اذكري إيجابيات تطبيق التقويم الإلكتروني.

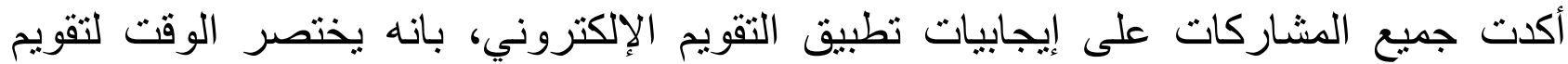

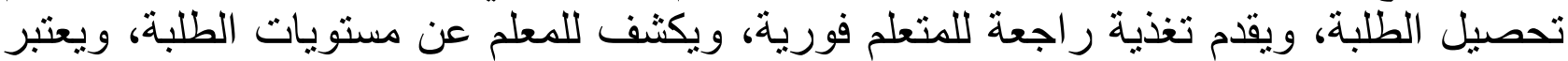

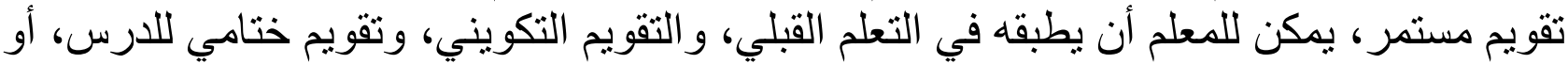

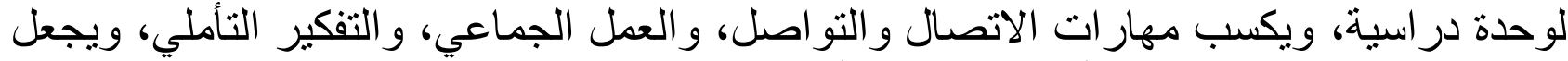

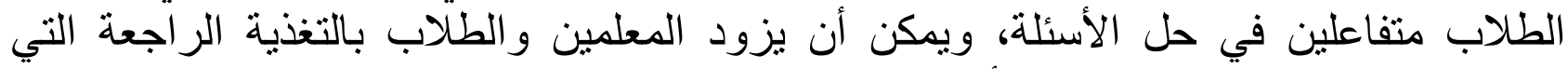

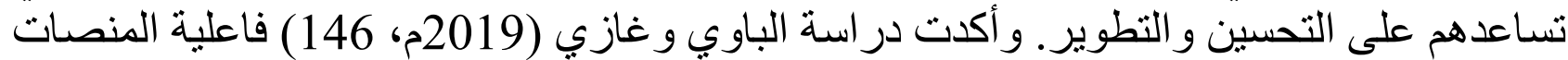

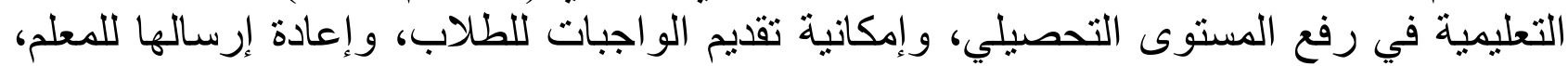

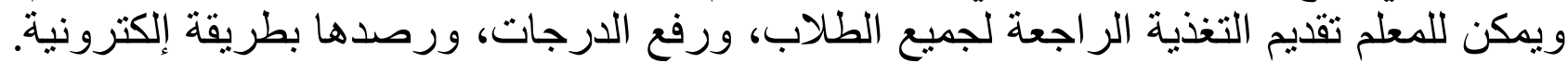
كذللك الدراسة التي قام بها التكنولوجية، لمحو الأمية الرقمية من حيث استخدام Google Drive لطلاب جامعة باتبة بانكوك.

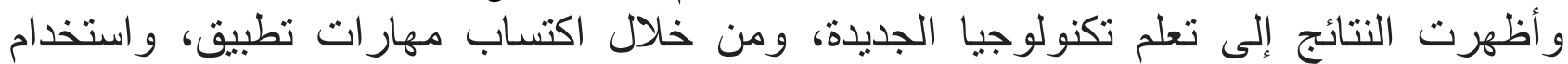
التكنولوجيا، وتقنية المعلومات.

كذللك اظهرت نتائج الدر اسة التي قام بها كلا من Guerrero \& other (2020) النتائج حول ممارسة

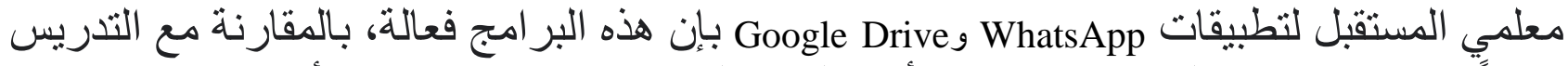

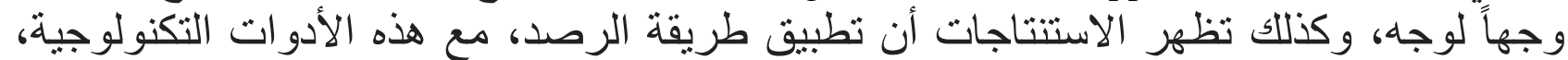

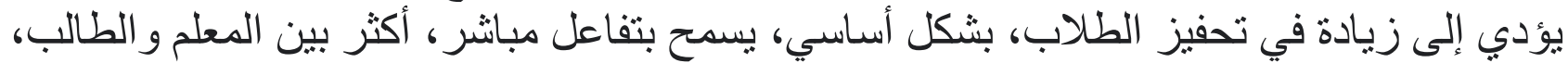

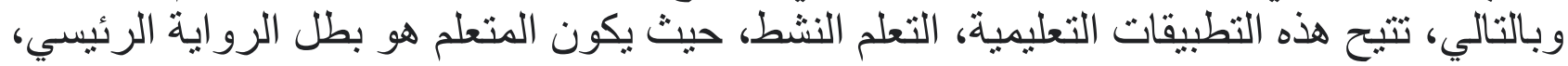

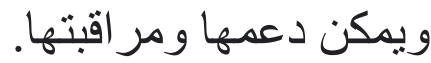

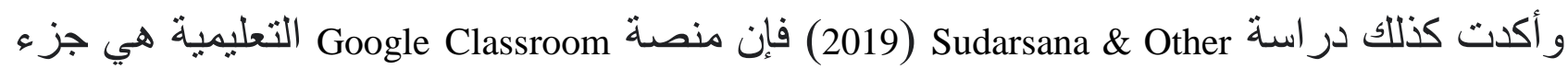

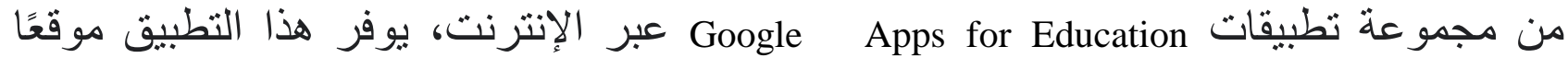

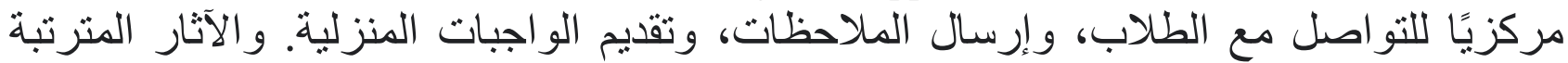

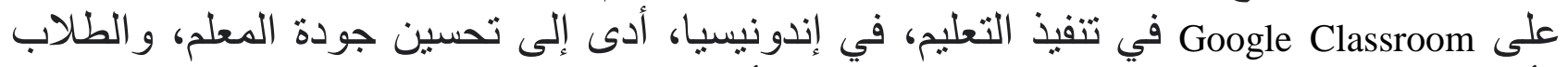

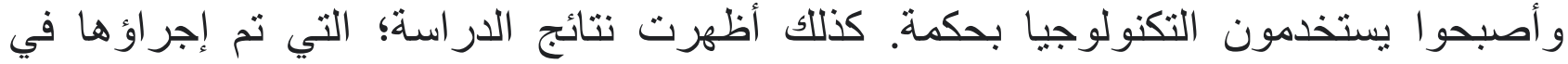

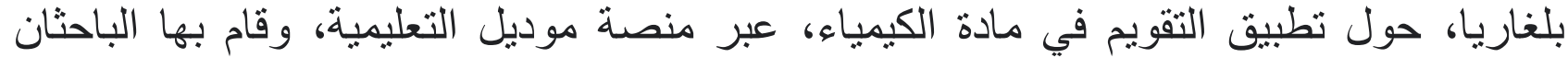
الإن 2018 (203) Angelov \& Traykova

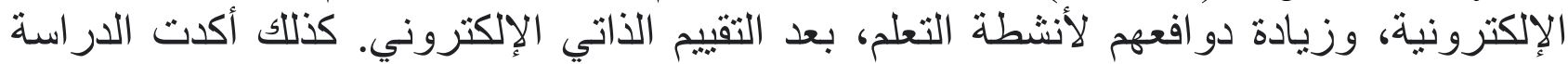

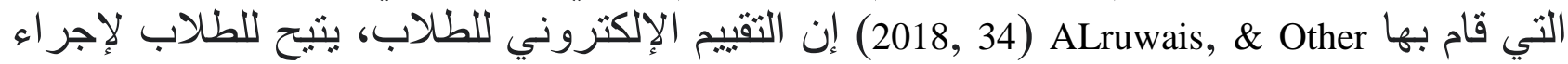

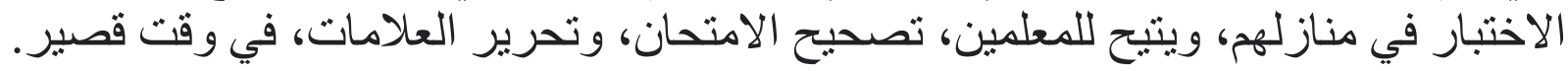
السؤال الثالث: ما لمعوقات التي واجهناك أثناء تطبيق أدوات التقويم الإلكتروني؟

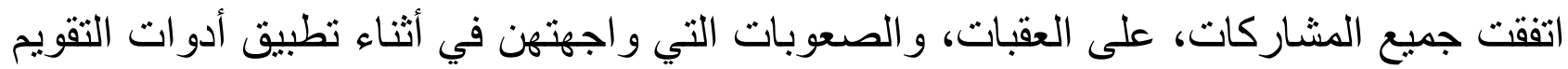

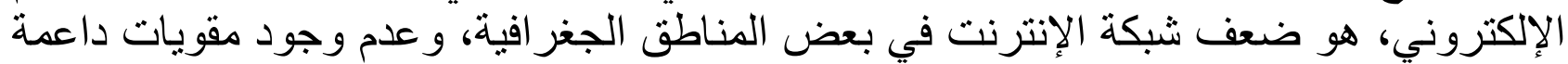
لنشبكة الإنترنت، مما جعل المعلمات يستخدمن شبكة هو اتفهن النقالة، لكي يتفادين هذه المشنية الثنلة، 
كذللك قامت بعض المشاركات مثل المعلمة أحلام وفاطمة بتقسيمهن إلى مجمو عات لتفادي نقص في الحواسيب في المدرسة. كذلك فإن القوانين التابعة لوزارة التربية، لا تسمح للطالب باستخدام الهو اتف الذكية داخل الفصول الدراسية. كذلك ذكرت المشاركات إن من العقبات كذلك عدم خبرة الطالبات في التعامل مع البرامج والتطبيقات الإلكترونية، ولكن مع التدريب قبل التقبيم النهائي لأداة التقويم؛ تم تدريبهن على استخدام البرامج من خلال إعطاء الطلاب مسابقات إلكترونية، و أسئلة تحفيزية تفاعلية مثل ما قامت به به المعلمة زوينة، و المعلمة شيماء، أما المعلمة أحلام و المعلمة عبير و علياء فقد دربت الطالبات من خلال الواجبات الإلكترونية، عن طريق ترئ تزويدهن

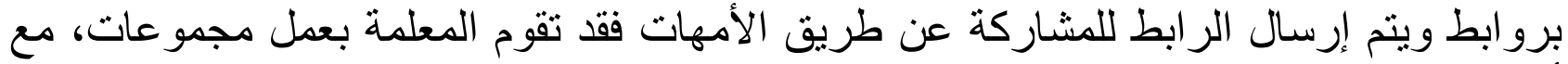

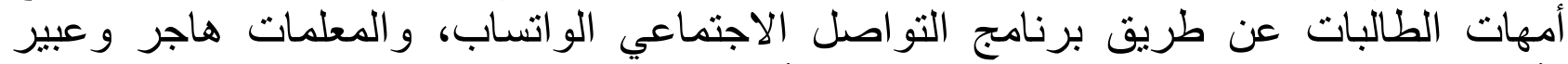
و أحلام قمن بتدريب الطالبات من خلال طرح أسئلة، عن طريق السبورة التفاعلية، ونتفق هذه

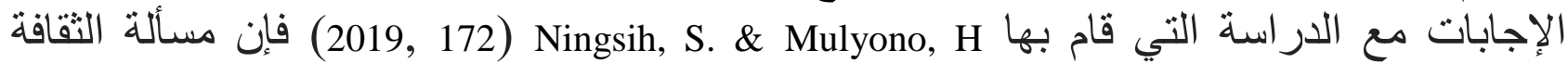
المدرسية تتعلق باستخدام الهو اتف الذكية في الفصل بالإضافة إلى القليل من الدعم التكنولوجي و الموارد بحتاج إلى معالجة للتنفيذ الناجح لمنثل هذه التطبيقات، مثل هذه القضايا قد تعيق المعلمين من تحقيق النجاح، في استخدام التكنولوجيا، من أجل نشاط التقيمٍ في سياق الفصل الدراسي.

\section{قائمة المراجع العربية:}

إسماعيل، مهند، يوسف، إبر اهيم، خليفة، أحمد. (2019م). فاعلية كُّل من الاختبار ات الإلكترونية و الاختبار ات الورقية في قياس التحصيل الأكاديمي: در اسة تجريبية على طالب ماجستير فئير التربية في تكنولوجيا التعليم بجامعة السودان للعلوم والتكنولوجيا. مجلة العلوم التربوية،

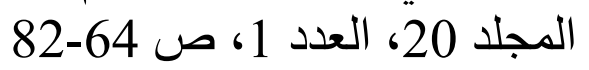

google الباوي، ماجدة إبراهيم، وغازي، باسل أحمد. (2019م). أثز استخدام المنصة التعليمية الإني تحصيل طلبة قسم الحاسبات لمادة image processing و اتجاهاتهم نحو التعليم الالكتروني. المجلة الدولية للبحوث في العلوم التربوية. المجلد2، العدد2، ص123-170 بسيوني، رفعت، حمد، أحمد، عبد الحميد، عبد العزيز. (2016م). "فاعلية بعض أدوات التقويم

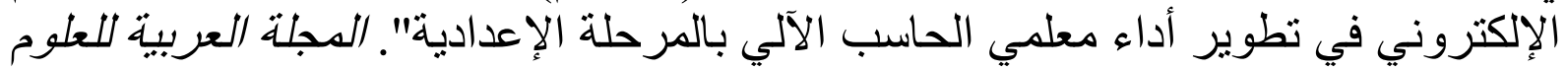

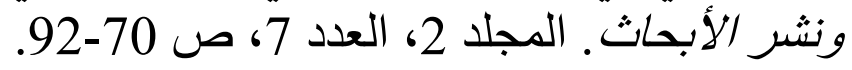

حنتولي، تغريد حمد تيسير. (2016). وافع التعلبم الإلكترونسي في جامعة النجاح الوطنية ودوره في تحقبق التفاعل بين المتعلمبن من وجهة نظر طلبة كلية الدراسات العلبا بر/مج كلبة التربية

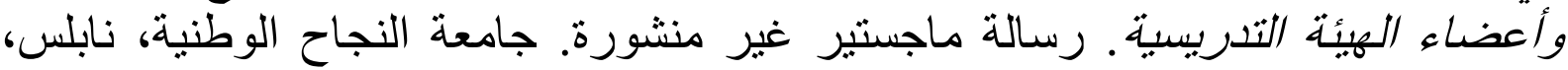
فلسطين.

الحبردي، شلاح عبدالله. (2017م) و اقع استخدام أدوات التقويم الإلكتروني لدى معلمي الدراسات الاجتماعية و الوطنية بالمرحلة الثانوية بمدينة الرياض وتهو وتصور مقتر ح لتطوير ها.

حسنين، خالد أحمد. (2017م). ملائمة استخدام الاختبارات الإلكترونية في التعليم المفتوح. رسالة دكتور اه غير منشورة، جامعة السودان للعلوم و التكنولوجيا، 


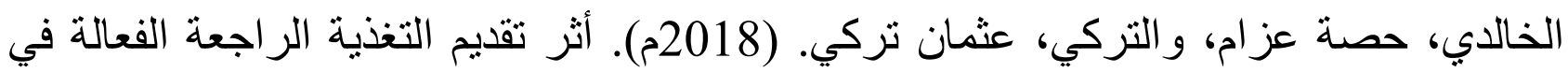

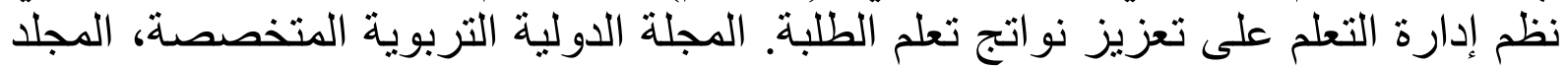

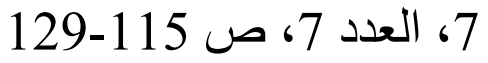

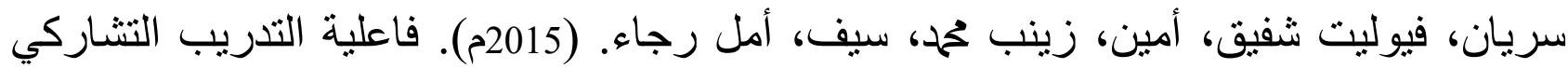

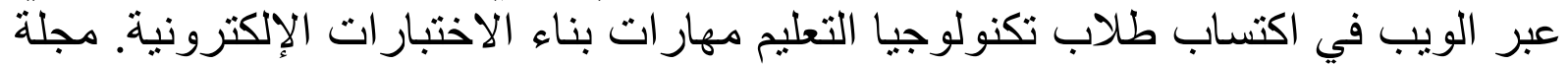

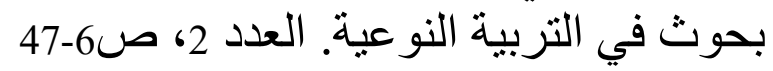

شامية، سحر رمضان. (2018م). فاعلية بيئة تعليمية إلكترونية في تنمية مهارات الإنة تصميم

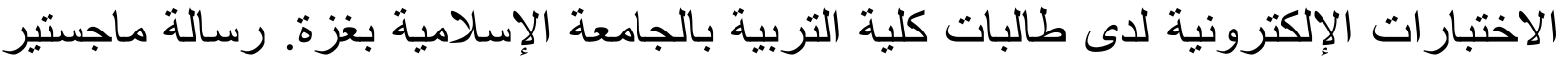
غير منشورة. الجامعة الإسلامية، غزة لإنة فلسطين.

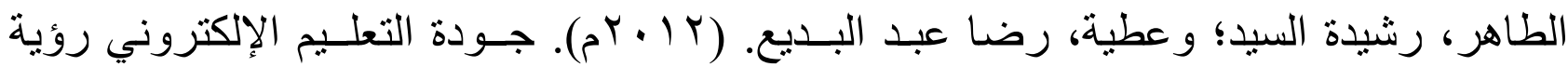
معاصرة. الإسكندرية :دار الجامعة الجديدة.

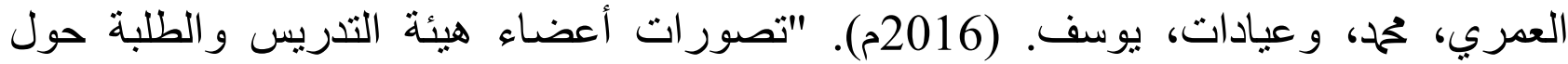

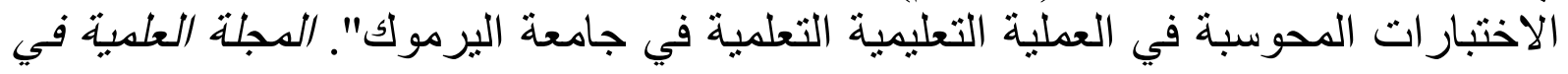

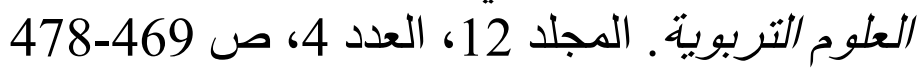

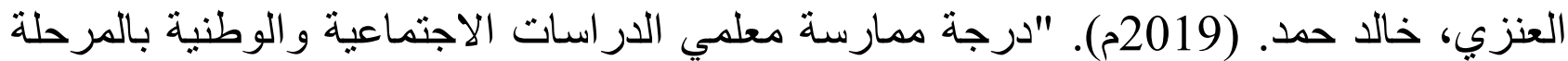

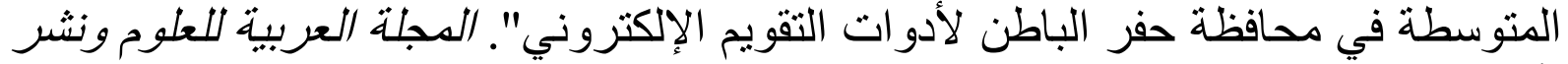

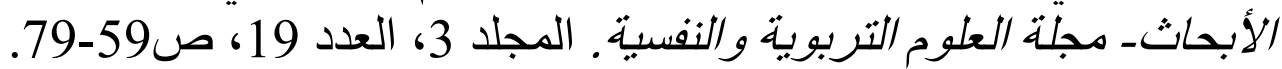

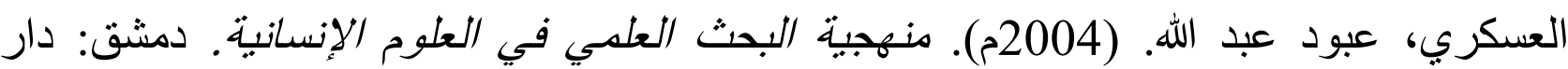
النمير.

عبد العاطي، حسن الباتع. (1437ه). "أنماط دعم الأداء وقياس أثر ها في إكساب أعضاء هيئة التدريس بجامعة الطائف مهار ات التقويم الإلكتروني باستخدام منظومة إدارة إدارة التعلم بلانكا

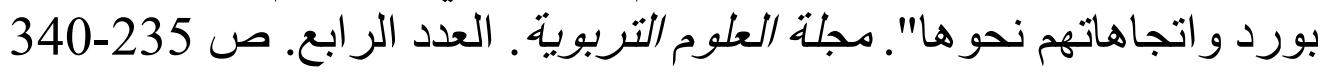

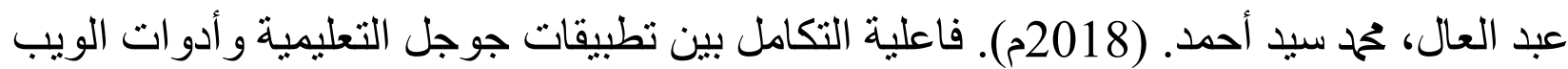

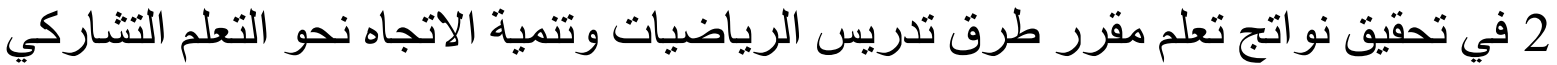

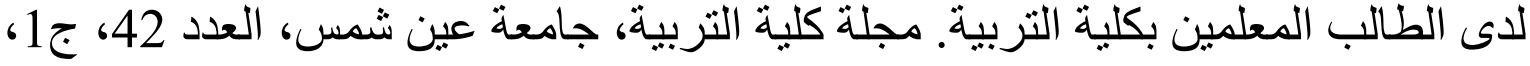
ص

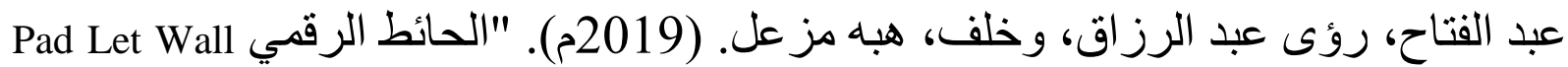

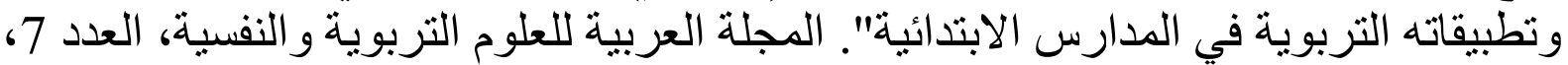
ص224-205 عبد المنعم، ر رانية عبد الله. (2020م). فاعلية توظيف الصفوف الرقمية في تنمية مهار ات استخدام

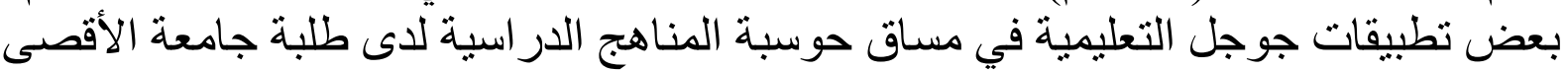

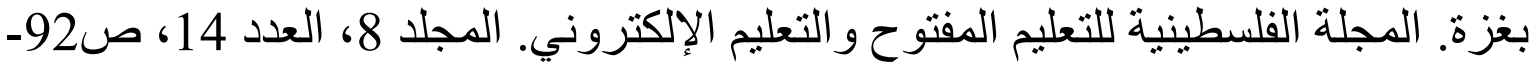
105

غانم، منجي عزمي. (2016م). إثر استخدم تطبيقات جوجل في تنمية اكتساب طلبة الصف 


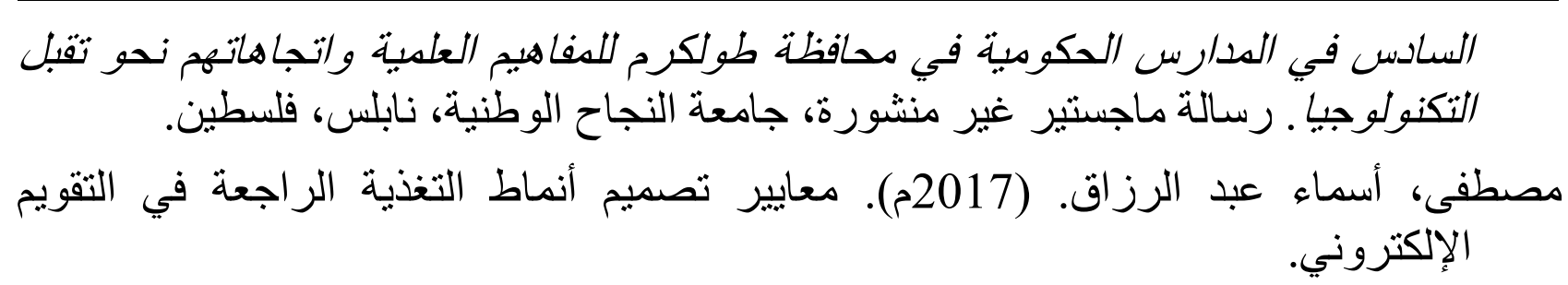

compunet platform.almanhal.com

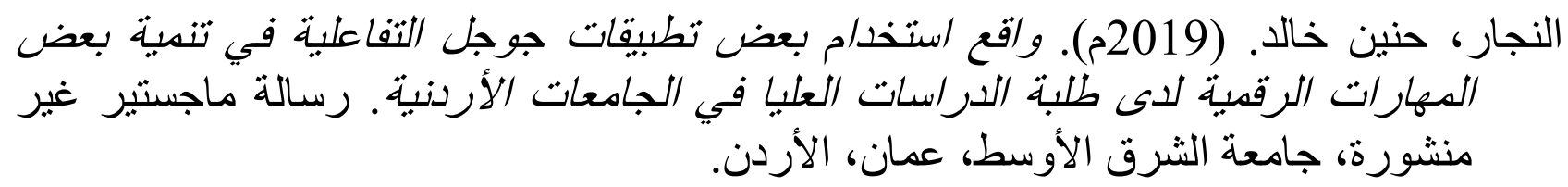

\section{ARABIC REFERENCES IN ROMAN ALPHABET}

'lismaeil, Mahnid, Yusif, 'librahim, Khalifat, 'Ahmid. (2019m). Faeiliatan Kunl Min Alaikhtibarat Al'iiliktruniat Walaikhtibarat Alwaraqiat Fi Qias Altahsil Al'akadimi: Dirasatan Tajribiat Ealaa Talab Majstyr Altarbiat Fi Tiknulujia Altaelim Bijamieat Alsuwdan Lileulum Waltiknulujia. Majalat Aleulum Altarbuiatu, Almujalad 20, Aleadad 1, S 64-82

Albawi, Majidat 'librahim, Waghazi, Basil 'Ahmad. (2019ma). 'Athar Aistikhdam Alminasat Altaelimiat Google Class Room Fi Tahsil Tlbt Qism Alhasibat Lamadat Image Processing Waitijahathum Nahw Altaelim Alalkatruni. Almajalat Alduwaliat Lilbihawth Fi Aleulum Altarbawiat. Almajald2, Aleadd2, Sa123-170

Basyuni, Rafeat, Muhamad, 'Ahmid, Eabd Alhamid, Eabd Aleaziz. (2016ma). "Faeliat Bed 'Adwat Altaqwim Al'iiliktrunii Fi Tatwir 'Ada' Muelimi Alhasib Alalii Bialmarhalat Al'iiedadiata". Almajalat Alearabiat Lileulum Wanashr Al'abhath. Almajalid 2, Aleadad 7, S 70-92.

Hintawli, Taghrid Muhamad Taysir. (2016ma). Waqie Altaelim Al'iiliktrunii Fi Jamieat Alnajah Alwataniat Wadawrih Fi Tahqiq Altafaeul Bayn Almutaealimayn Min Wijhat Nazar Tlbt Kuliyat Aldirasat Aleulya Baramij Kuliyat Altarbiat Wa'aeda' Alhayyat Altadrisiati. Risalat Majstayr Ghyr Manshurati. Jamieat Alnajah Alwataniati, Nabulus, Filastin.

Alhabrdi, Shilah Eibdallih. (2017ma) Waqie Aistikhdam 'Adwat Altaqwim Al'iiliktrunii Ladaa Muelimi Aldirasat Alaijtimaeiat Walwataniat Bialmarhalat Alththanawiat Bimadinat Alriyad Watasawur Muqtarah Litatwiriha.

Hasnayn, Khalid 'Ahmid. (2017m). Mulayimat Aistikhdam Alaikhtibarat Al'iiliktruniat Fi Altaelim Almaftuhi. Risalat Dukturah Ghyr Manshurat, Jamieat Alsuwdan Lileulum Waltiknulujia,

Alkhalidi, Hisat Eazam, Waltarki, Euthman Turki. (2018ma). 'Athar Taqdim Altaghdhiat Alraajieat Alfaeealat Fi Nazam 'lidarat Altaealum Ealaa Taeziz Nawatij Taelam Altalabata. Almajalat Alduwaliat Altarbawiat Almutakhasisat, Almajalid 7, Aleadad 7, S 115-129

Sariani, Fywlyt Shfyq, 'Aminun, Zaynab Muhmidun, Sayif, 'Amal Raja'. (2015m). Faeiliat Altadrib Altasharukii Eabr Alwayb Fi Aiktisab Tullab Tiknulujia Altaelim Maharat Bina' Alaikhtibarat Al'iiliktruniati. Majalat Bihawth Fi Altarbiat Alnaweiatu. Aleadad 2, S6-47

Shamiat, Sihr Ramadan. (2018). Faeiliat Bayyat Taelimiat 'liliktruniat Fi Tanmiat Maharat Tasmim Alaikhtibarat Al'iiliktruniat Ladaa Talibat Kuliyat Altarbiat Bialjamieat Al'iislamiat Bighazati. Risalat Majstayr Ghyr Minshurat. Aljamieat Al'iislamiati, Ghazat, Filastin. Altaahiru, Rashidat Alsiyda; Waeatiat,

Ridaan Eibad Albdye. (2012). Jawidat Altelym Al'iiliktrunii Ruyat Mueasirat. Al'iiskandariat: Dar Aljamieat Aljadidat.

Aleamariu, Muhmid, Waeiadat, Yusif. (2016). "Tsurat 'Aeda' Hayyat Altadris Waltalabat Hawl Alaikhtibarat Almuhwsabat Fi Aleamaliat Altaelimiat Altaelamiat Fi Jamieat Alyarmuka". Almajalat Aleilmiat Fi Aleulum Altarbawiat. Almajalad 12, Aleadad 4, S 469-478

Aleinziu, Khalid Hamd. (2019). "Drajat Mumarasatan Muelimiu Aldirasat Alaijtimaeiat Walwataniat Bialmarhalat Almutawasitat Fi Muhafazat Hfr Albatn Li'adwat Altaqwim Al'ilktruni". Almajalat Alearabiat Lileulum Wanashr Al'abhathi- Majalat Aleulum Altarbawiat Walnafsiat. Almajalid 3, Aleadad 19, Sa59-79. 
Aleaskariu, Eabuwd Eabd Allh. (2004ma). Manhajiat Albahth Aleilmii Fi Aleulum Al'iinsaniati. Damshqa: Dar Alnamir.

Eabd Aleati, Hasan Albatie. (1437ha). "Anamat Daem Al'ada' Waqias 'Athariha Fi 'liksab 'Aeda' Hayyat Altadris Bijamieat Alttayif Maharat Altaqwim Al'iliktrunii Biastikhdam Manzumat 'lidarat Altaelum Blak Biward Waitijahatihim Nahwaha". Majalat Aleulum Altarbawiat. Aleadad Alraabie. S 235-340

Eabd Aleali, Muhamad Syd 'Ahmad. (2018ma). Faeiliat Altakamul Bayn Tatbiqat Jujl Altaelimiat Wa'adawat Alwayb 2 Fi Tahqiq Nawatij Taelam Muqarar Turuq Tadris Alriyadiaat Watanmiat Alaitijah Nahw Altaelim Altasharukii Ladaa Altaalib Almuealimin Bikaliat Altarbiati. Majalat Kuliyat Altarbiati, Jamieat Eayan Shams, Aleadad 42, Ja1, S 261-338

Eabd Alfatah, Ruaa Eabd Alrazaq, Wakhalfa, Habih Mazeal. (2019m). "Alhayit Alraqamia Pad Let Wall Watatbiqatih Altarbawiat Fi Almadaris Alaibtidayiyata". Almajalat Alearabiat Lileulum Altarbawiat Walnafsiati, Aleadad 7, Sa205-224

Eabd Almnem, Raniat Eabd Allh. (2020ma). Faeiliat Tawzif Alsufuf Alraqamiat Fi Tanmiat Maharat Aistikhdam Bed Tatbiqat Jujl Altaelimiat Fi Misaq Hawsibat Almanahij Aldirasiat Ladaa Tlbt Jamieat Al'aqsaa Bighazatu. Almajalat Alfilastiniat Liltaelim Almaftuh Waltaelim Al'iiliktruni. Almajalid 8, Aleadad 14, Sa92-105

Ghanim, Manajiy Eazmi. (2016ma). 'lithr Aistikhdam Tatbiqat Jujl Fi Tanmiat Aiktisab Tlbt Alsafi Alssadis Fi Almadaris Alhukumiat Fi Muhafazat Tulkarm Lilmafahim Aleilmiat Waitijahatihim Nahw Tuqbal Altiknuliwjia. Risalat Majsatayr Ghyr Manshurati, Jamieat Alnajah Alwataniati, Nabulus, Filastin.

Mustafaa ،'Asma' Eabd Alrazaqi. (2017ma). Maeayir Tasmim 'Anmat Altaghdhiat Alraajieat Fi Altaqwim Al'iilktruni: compunet platform.almanhal.com.

alnujaru, hunayn khalid. (2019ma). waqie aistikhdam bed tatbiqat jujil altafaeuliat fi tanmiat bed almiharat alraqamiat ladaa tlbt aldirasat aleulya fi aljamieat al'urduniyati. risalat majstayr ghyr manshurat, jamieat alshrq al'awsati, eumaan, al'urdunn.

\section{REFERENCE LIST}

ALqahtani, Abdullah. (2019). Usability testing of Google cloud applications: student's perspective. Journal of technology and science education. 9. (3). p 326-339.

Angelov, Radoslav \& Traykova, Silvia. (2018). Electronic Assessment and Self-assessment of Students in Chemistry and Environmental Protection. Science, Engineering \& Education, 3, (1), p 63-67

ALruwais, Nuha, Wills, Gary, and Wald, Mike. (2018). Advantages and Challenges of Using e-Assessment. International Journal of Information and Education Technology. 8, (1), p:34-37.

Krisawan Prasertsith, krisawan, Kanthawongs, pen Jira, and Tan Limpachote. (2016). Students' Google Drive Intended Usage: A Case Study Of Mathematics Courses In Bangkok University. 13th International Conference on Cognition and Exploratory Learning in Digital Age (CELDA 2016). ISBN: 978-989-8533-55-5.

Ningsih, S. \& Mulyono, H. (2019). Digital Assessment Resources in Primary and Secondary School Classrooms: Teachers' Use and Perceptions. International Association of Online Engineering, Vol. 13, No. 8, p 167-173 https://www.learntechlib.org/p/216529/

Owayld, Ali Mahdi, Uden, Lorna. (2014). The Usage of Google Apps Services in Higher Education, Conference: 9th. International Knowledge Management Organization conference KMO 2014.At: Communications in Computer and Information Science, Volume: 446, (pp 95-104)

Sudarsana, Ketut, Putra, Ida, \& Other. (2019). The use of Google classroom in the learning process. 1st International Conference on Advance and Scientific Innovation (ICASI). Journal of Physics: Conference Series. doi:10.1088/1742-6596/1175/1/012165.p(1-6).

Singh, Villiers, de, (Ruth). (2017). An Evaluation Framework and Instrument for Evaluating e-Assessment Tools. International Review of Research in Open and Distributed Learning Volume 18, Number 6, $p$ (164-185). 